Aus der Klinik für Allgemeine Innere Medizin

(Chefarzt Prof. Dr. med. P. G. Lankisch)

des Medizinischen Zentrums (Leitung Prof. Dr. med. P. G. Lankisch)

des Städtischen Klinikums Lüneburg

\title{
Exokrine Pankreasinsuffizienz bei Patienten mit terminaler Niereninsuffizienz unter einer Hämodialyse-Therapie
}

\author{
INAUGURAL-DISSERTATION \\ zur Erlangung des Doktorgrades \\ der Medizinischen Fakultät \\ der Georg-August-Universität zu Göttingen
}

vorgelegt von

Jochen Griesche-Philippi

aus Bad Wildungen

Göttingen 2009 
Dekan:

1. Berichterstatter:

2. Berichterstatter/in:

3. Berichterstatter/in:

Tag der mündlichen Prüfung:
Prof. Dr. med. C. Frömmel

Prof. Dr. med. P. G. Lankisch 
1. Einleitung 5

$\begin{array}{lll}2 . & \text { Patienten und Methodik } & 8\end{array}$

2.1. Patienten 8

2.2. Methodik 8

2.2.1. Berechnung des Body Mass Index (BMI) 8

2.2.2. Fäkale Elastase-1-Messung mit einem monoklonalen Test 9

2.2.2.1. Testprinzip 9

2.2.2.2. Durchführung 10

2.2.2.3. Bewertung 12

2.2.3. Fäkale Elastase-1-Messung mit einem polyklonalen Test 12

2.2.3.1. Testprinzip 13

2.2.3.2. Durchführung 13

2.2.3.3. Bewertung 16

2.2.4. Stuhlgewichtsbestimmung 16

2.2.5. Quantitative Stuhlfettanalyse 17

2.2.5.1. Durchführung 17

2.2.5.2. Bewertung 18

2.3. Statistik 19

$\begin{array}{ll}2.4 . \quad \text { Ethik-Votum } & 19\end{array}$

$\begin{array}{lll}3 . & \text { Ergebnisse }\end{array}$

3.1. Demografische Angaben der Patienten 20

3.2. Messergebnisse der Patienten 29

3.3. Elastase-1-Messungen im Stuhl 29

3.3.1. Bioserv-Diagnostics-Methode 29

3.3.2. ScheBo-Biotech-Methode 29 
3.4. Exokrine Pankreasinsuffizienz versus Geschlecht und Alter, Body Mass Index (BMI), Dialysedauer sowie Ursache der terminalen Niereninsuffizienz der Patienten

3.5. Stuhlgewichts- und Stuhlfettbestimmung

3.6. Stuhlgewichts- und Stuhlfettmessergebnisse versus Elastase-1-Messergebnisse im Stuhl

3.7. Stuhlgewichts- und Stuhlfettmessergebnisse versus Therapie mit Phosphatbindern

4.

Diskussion

4.1. Diagnostik der exokrinen Pankreasinsuffizienz 41

4.2. Diagnostik einer Diarrhoe und/oder Steatorrhoe 48

4.3. Das Pankreas bei Niereninsuffizienz 50

4.3.1. Morphologische Untersuchungen des Pankreas bei Niereninsuffizienz

4.3.2. Funktionsuntersuchungen des Pankreas bei Niereninsuffizienz

4.4. Diarrhoe und Steatorrhoe bei Niereninsuffizienz 56

4.5. Schlussfolgerungen 59

$\begin{array}{lll}\text { 5. Zusammenfassung } & 61\end{array}$

6. Literaturverzeichnis 64 


\section{Einleitung}

Die Beziehungen zwischen Pankreas- und Nierenerkrankungen wurden schon vor Jahrzehnten untersucht beziehungsweise sind schon seit langem bekannt (Schimmelpfennig u. Schimmelpfennig 1969).

Wahrscheinlich als Erster berichtete Rasumowsky (1899) über eine Anurie als Komplikation einer schweren akuten Pankreatitis. Auch später wurde mehrfach über die Häufigkeit des akuten Nierenversagens bei akuter Pankreatitis berichtet und geschildert, wie häufig diese Komplikation in den einzelnen Zentren auftritt (Übersicht bei Schimmelpfennig u. Schimmelpfennig 1969).

In den letzten Jahren galt ein erhöhtes Kreatinin ( $>2 \mathrm{mg} / \mathrm{dl}$ nach Rehydratation) nach den Atlanta-Kriterien als ein Zeichen einer schweren Erkrankung (Bradley III 1994). Kürzlich wurde ein erhöhtes Serum-Kreatinin bei Aufnahme als Hinweis auf Pankreasnekrosen beschrieben (Talamini et al. 1999). Auch wenn dies zurzeit noch umstritten ist, gilt, dass bei einem normalen Serum-Kreatinin bei Aufnahme eine kontrastmittelverstärkte Computertomografie (CT) zum Nachweis von Pankreasnekrosen nicht nötig ist, weil diese bei dieser Konstellation nicht auftreten (Lankisch et al., 2009, eingereicht Am. J. Gastroenterol.). Zusammen mit einem normalen Untersuchungsbefund des Bauches und einem normalen SerumHämatokrit bei Aufnahme gilt auch ein normaler Serum-Kreatininwert bei Aufnahme als Hinweis auf einen harmlosen Verlauf der Pankreatitis und ist zusammengefasst im "Harmless Acute Pancreatitis Score" (HAPS) (Lankisch et al. 2009).

Bei Dialyse, speziell bei chronischen Peritonealdialyse-Patienten, besteht ein erhöhtes Risiko für die Patienten, an einer akuten Pankreatitis zu erkranken (Bruno et al. 2000; Quraishi et al. 2005; Lankisch et al. 2008), ohne dass genau geklärt ist, warum dieses Risiko besteht. 
Ferner wurde eine Substanz, das Phenacetin, das früher häufig Bestandteil von Kopfschmerztabletten war, als Ursache einer interstitiellen Nephritis identifiziert. Offensichtlich führte dieses Analgetikum nicht nur zu einer Nierenschädigung, sondern auch zu einer chronischen Pankreatitis (Ammann et al. 1981; Wisotzky et al. 1996).

Unabhängig von einer akuten oder chronischen Pankreatitis wurde in den 70 er bis 80er Jahren mehrfach untersucht, ob bei einer chronischen Niereninsuffizienz auch eine exokrine Pankreasinsuffizienz vorliegt und ob diese möglicherweise für den schlechten Ernährungszustand der DialysePatienten in damaliger Zeit verantwortlich war. Mehrere Untersucher (Wittich et al. 1968; Bartos et al. 1970; Gerhardt et al. 1974; Poll et al. 1979) konnten mithilfe des Sekretin-Pankreozymin-Tests (SPT) beziehungsweise eines seiner Modifikationen zeigen, dass ein sehr hoher Prozentsatz von niereninsuffizienten Patienten unter einer exokrinen Pankreasinsuffizienz leidet. Diese Studien führten jedoch nicht zu klinischen Konsequenzen, weil nicht untersucht wurde, ob die exokrine Pankreasinsuffizienz noch kompensiert (keine Steatorrhoe) oder bereits dekompensiert (Steatorrhoe vorhanden) war. Im letzteren Fall wäre es für niereninsuffiziente Patienten entscheidend, eine entsprechende Therapie zu erfahren, um Spätfolgen der exokrinen Pankreasinsuffizienz wie Osteoporose, Nachtblindheit und andere nicht erleiden zu müssen.

Da der SPT ein sehr aufwendiger und kostspieliger Test ist, wird er praktisch weltweit nicht mehr durchgeführt. Als Goldstandard zur Überprüfung der exokrinen Pankreasfunktion gilt jetzt die Elastase-1-Messung im Stuhl. Für diesen Test sind zwei verschiedene Messverfahren beschrieben worden, die beide in dieser Studie angewendet wurden.

Primäres Studienziel der hier vorgelegten Untersuchung war es, mithilfe dieser relativ neuen indirekten Pankreasfunktionstests festzustellen, wie viele chronische Hämodialyse-Patienten an einer exokrinen Pankreasinsuffizienz leiden. Sekundäres Ziel war es, in dieser Studienpopulation den Schweregrad der exokrinen Pankreasinsuffizienz zu etablieren. Aufgrund 
dieses sekundären Ziels war es notwendig, bei diesen Patienten das Stuhlgewicht und den Stuhlfettgehalt zu bestimmen und den Anteil chronischer Hämodialyse-Patienten festzulegen, bei denen es zu einer Diarrhoe beziehungsweise Steatorrhoe kommt. 


\section{Patienten und Methodik}

\subsection{Patienten}

Die hier vorgelegte Untersuchung umfasst 50 Patienten, die wegen einer terminalen Niereninsuffizienz hämodialysiert werden.

Bei allen Patienten wurde vor Aufnahme in die Studie mit einer TSH( Thyreoidea stimulierendes $\underline{H}$-rmon-)Bestimmung eine Schilddrüsenüberfunktion und durch eine sorgfältige Ultrasonografie eine chronische Pankreatitis nach den Cambridge-Kriterien (Sarner u. Cotton 1984a. b) ausgeschlossen. Außerdem wurden keine Patienten in die Studie aufgenommen, bei denen ein Zustand nach Magenresektion (mögliche postzibale Asynchronie) oder nach Dünndarm-(teil-)resektion vorlag. Ferner wurden die Patienten ausgeschlossen, bei denen anamnestisch eine chronisch-entzündliche Darmerkrankung mit Beteiligung des terminalen Ileums bekannt war. In den beiden letzteren Fällen wäre eine fehlende Rückresorption von Gallensäuren möglich, die ihrerseits bei der Mizellenbildung im Duodenum gefehlt hätten, was zu einer Steatorrhoe hätte führen können (dekompensiertes Gallensäureverlustsyndrom). Auch wurden Patienten, die geistig und körperlich nicht in der Lage waren, eine sorgfältige Stuhlsammlung über 3 Tage durchzuführen, nicht in die Studie einbezogen.

\subsection{Methodik}

\subsubsection{Berechnung des Body Mass Index (BMI)}

Wie üblich wurde die Messung des BMI nach folgender Formel vorgenommen: Kilogramm durch Quadratmeter. Ein Normalgewicht lag vor, wenn der BMI zwischen 20 und 25 lag, ein Übergewicht bei einem BMI von $>25-30$ und eine Adipositas bei einem BMI $>30$. 


\subsubsection{Fäkale Elastase-1-Messung mit einem monoklonalen Test}

Die Testkits zur Bestimmung der Pankreas-Elastase-1 werden von der Firma ScheBo-Biotech AG (Netanyastr. 3, 35394 Giessen) hergestellt.

Bei der Untersuchungsmethode der Firma ScheBo-Biotech handelt es sich um ein so genanntes Sandwich-ELISA (Enzyme Linked Immuno Sorbent Assay) mit zwei monoklonalen Antikörpern, die hochspezifisch die pankreatische Elastase-1 erkennen. Sensitivität und Spezifität werden jeweils mit $93 \%$ angegeben.

Die Haltbarkeit der zu verwendenden Stuhlproben wird bei Kühlschranklagerung mit $4-8^{\circ} \mathrm{C}$ und 3 Tagen angegeben, tief gefroren bei $-20^{\circ} \mathrm{C}$ können die Proben ein Jahr lang aufbewahrt werden.

Nach Angaben der Herstellerfirma zeigen Werte $>200 \mu \mathrm{g}$ Elastase/g Stuhl bei den Referenzkonzentrationen eine normale exokrine Pankreasfunktion an, Werte unter $200 \mu \mathrm{g}$ eine exokrine Pankreasinsuffizienz.

Die Elastase kann in einem Messbereich zwischen 15 und $500 \mu$ g Elastase$1 / \mathrm{g}$ Stuhl bestimmt werden, Werte darunter oder darüber sollen mit $<15$ oder $>500 \mu \mathrm{g} / \mathrm{g}$ Stuhl angegeben werden.

Der mittlere Variationskoeffizient der Methode liegt nach Angaben der Herstellerfirma bei 5,8\%.

\subsubsection{Testprinzip}

Die ELISA-Platte ist mit einem spezifischen monoklonalen Antikörper, der ausschließlich humane Elastase-1 erkennt, bestückt. Die Elastase-1 aus einer Stuhlprobe oder einem Standard wird durch Bindung an diesen Antikörper immobilisiert.

Im nächsten Schritt erfolgt eine Inkubation mit einem monoklonalen AntiE1-Biotin-Peroxidase-(POD-)Streptavidin-Komplex. Die darin enthaltene Peroxidase oxidiert das Substrat ABTS (2,2'-Azino-bis-(3-ethylbenzothiazolin-6-sulfonsäure). Anschließend erfolgt die fotometrische Bestimmung des oxidierten ABTS. 


\subsubsection{Durchführung}

Vorbereitungsarbeiten. Zur Bestimmung genügt eine erbsengroße Stuhlprobe, die vorher extrahiert und verdünnt wurde.

Der Extraktionspuffer wird aus dem im Testkit enthaltenen Extraktionspuffer hergestellt, wobei $100 \mathrm{ml}$ mit $400 \mathrm{ml}$ Aqua bidest. verdünnt werden.

Das Einwiegen der Stuhlproben erfolgte mit dem Probenvorbereitungssystem der Firma Roche, wobei eine genaue Einwaage mit einer Impföse sowie einer digitalen Laborwaage durchgeführt wurde. Etwa 100 mg Stuhl werden in die Einweg-Probenröhrchen verbracht. Der eingewogenen Stuhlmenge entsprechend wird der vorbereitete Extraktionspuffer zugegeben (z. B. $10 \mathrm{ml}$ Puffer zu $100 \mathrm{mg}$ Stuhl, 7,5 ml Puffer zu $75 \mathrm{mg}$ Stuhl etc.).

Diese Proben werden dann mittels eines Reagenzglasschüttelgerätes vorgemixt, anschließend in einem Schüttler (z. B. IKA-VIBRAX VXR basic) ca. 30 min geschüttelt und über Nacht in einen Kühlschrank $\left(4-8^{\circ} \mathrm{C}\right)$ gestellt. Am nächsten Morgen erfolgt ein erneutes Durchmischen mittels Schüttler, dann wartet man, bis sich die Schwebstoffe am Boden abgesetzt haben.

Anschließend erfolgt die weitere Verdünnung der Proben mit dem im Testkit enthaltenen Proben-/Waschpuffer, wobei durch das Zusammenbringen von jeweils $10 \mu \mathrm{l}$ Stuhlprobenextrakt und $2,5 \mathrm{ml}$ Proben/Waschpuffer eine 1:250-Verdünnung erzeugt wird.

Probeninkubation: Jetzt beginnt die eigentliche Durchführung: Es werden jeweils $50 \mu \mathrm{l}$ Stuhlextrakte, Standards oder Kontrollen nach dem entsprechenden Pipettierschema (siehe unten) in einen der enthaltenen ELISAStreifen mit 96 Vertiefungen pipettiert. Der Streifen ist mit dem monoklonalen Antikörper gegen humane Elastase-1 beschichtet.

Die Proben werden dann 30 min bei Raumtemperatur inkubiert.

Anschließend erfolgt das Waschen, wobei der Inhalt der Vertiefungen verworfen und anschließend $3 \mathrm{x}$ mit Proben-/Waschpuffer pro Vertiefung 
gewaschen wird (jeweils $250 \mu$ über eine Pipette). Man lässt den Puffer 1-2 min einwirken, anschließend werden die Flüssigkeitsreste durch vorsichtiges Ausklopfen auf Papiertücher entfernt.

Danach erfolgt die Zugabe von jeweils $50 \mu \mathrm{l}$ des mitgelieferten gebrauchsfertigen monoklonalen Anti-Elastase-1-Biotin-POD-StreptavidinKomplexes pro Vertiefung und die erneute Inkubation bei Raumtemperatur über 15 min. Es erfolgt wiederum eine Waschung, wie oben beschrieben.

Anschließend wird die Farbreaktion erzeugt, indem jeweils $100 \mu \mathrm{l}$ der gebrauchsfertigen ABTS-Substratlösung in die Vertiefungen gegeben und erneut über 15 min bei Raumtemperatur und Dunkelheit inkubiert werden.

Danach erfolgt die Zugabe der gebrauchsfertigen Stopplösung (jeweils $100 \mu \mathrm{l})$.

\section{Angewendetes Pipettierschema bei der Testdurchführung:}

\begin{tabular}{|l|l|l|l|l|l|l|l|l|l|l|l|l|}
\hline & $\mathbf{1}$ & $\mathbf{2}$ & $\mathbf{3}$ & $\mathbf{4}$ & $\mathbf{5}$ & $\mathbf{6}$ & $\mathbf{7}$ & $\mathbf{8}$ & $\mathbf{9}$ & $\mathbf{1 0}$ & $\mathbf{1 1}$ & $\mathbf{1 2}$ \\
\hline A & Blank & Blank & P 3 & P 3 & P 11 & P 11 & P 19 & P 19 & P 27 & P 27 & P 35 & P 35 \\
\hline B & S 1 & S 1 & P 4 & P 4 & P 12 & P 12 & P 20 & P 20 & P 28 & P 28 & P 36 & P 36 \\
\hline C & S 2 & S 2 & P 5 & P 5 & P 13 & P 13 & P 21 & P 21 & P 29 & P 29 & P 37 & P 37 \\
\hline D & S 3 & S 3 & P 6 & P 6 & P 14 & P 14 & P 22 & P 22 & P 30 & P 30 & P 38 & P 38 \\
\hline E & S 4 & S 4 & P 7 & P 7 & P 15 & P 15 & P 23 & P 23 & P 31 & P 31 & P 39 & P 39 \\
\hline F & K & K & P 8 & P 8 & P 16 & P 16 & P 24 & P 24 & P 32 & P 32 & P 40 & P 40 \\
\hline G & P 1 & P 1 & P 9 & P 9 & P 17 & P 17 & P 25 & P 25 & P 33 & P 33 & P 41 & P 41 \\
\hline H & P 2 & P 2 & P 10 & P 10 & P 18 & P 18 & P 26 & P 26 & P 34 & P 34 & P 42 & P 42 \\
\hline
\end{tabular}

$\mathrm{S}=$ Standard $; \mathrm{K}=$ Kontrolle; $\mathrm{P} 1-\mathrm{P} 42=$ Patientenkontrollen

Auswertung der Ergebnisse: Die fotometrische Messung wird bei einer Wellenlänge von $405 \mathrm{~nm}$ innerhalb von 5-30 min nach Zugabe der Stopplösung durchgeführt, wobei die Messplatte vor der Messung nochmals geschüttelt wird. 
Anschließend erfolgt die quantitative Auswertung, wobei zunächst anhand der gemessenen Standards eine Standardkurve erzeugt wird. In einem Koordinatensystem wird dabei auf der $\mathrm{x}$-Achse die Konzentration, an der $y$-Achse die jeweilige Absorption aufgetragen (log-log). Anhand der so erzeugten Standardkurve können die Werte der Patientenstuhlproben abgelesen werden.

\subsubsection{Bewertung}

Werte von $>200 \mu \mathrm{g}$ Elastase/g Stuhl zeigen eine normale exokrine Pankreasfunktion an und Werte zwischen 100 und $200 \mu \mathrm{g}$ eine leichte bis mäßig schwere exokrine Pankreasinsuffizienz. Bei Werten von $<100 \mu \mathrm{g}$ liegt eine schwere, in der Regel pankreasenzymsubstitutionsbedürftige exokrine Pankreasinsuffizienz vor.

\subsubsection{Fäkale Elastase-1-Messung mit einem polyklonalen Test}

Die Testkits werden von der Firma Bioserv Diagnostics GmbH (Dr.-LorenzWeg 1, 18059 Rostock) hergestellt und von der Firma Hain Lifescience GmbH (Hardwiesenstraße 1, 72174 Nehren) vertrieben.

Bei dem Test handelt es sich um ein Festphasen-Enzymimmunoassay (Enzyme Linked Immuno Sorbent Assay = ELISA) zur quantitativen Bestimmung pankreatischer Elastase im Stuhl und Diagnose einer exokrinen Pankreasinsuffizienz auf der Basis der Doppelsandwich-Technik. Verwendet werden zwei polyklonale Antikörpergemische. Als Antigen für die Immunisierung werden synthetische Peptidsequenzen aus der menschlichen Pankreaselastase eingesetzt.

Die Antikörper sind in der Lage, jeweils zahlreiche verschiedene Epitope auf genau definierten spezies- und organspezifischen Elastase-Aminosäuresequenzen zu erkennen.

Durch das Detektieren zahlreicher unterschiedlicher Epitope wird die Sensitivität und Spezifität erhöht. Die diagnostische Spezifität wird mit 95\% angegeben, die diagnostische Sensitivität beträgt $94 \%$ für eine schwere 
chronische Pankreatitis (Werte $<100 \mu \mathrm{g}$ pankreatische Elastase/g Stuhl) und $63 \%$ für eine mittlere bis leichte chronische Pankreatitis $(100-200 \mu \mathrm{g}$ pankreatische Elastase/g Stuhl).

Die intraseriellen Variationskoeffizienten liegen bei 5,2\% für die Entscheidungsgrenze $100 \mu \mathrm{g}$ Elastase/g Stuhl und bei 4,3\% für die Entscheidungsgrenze $200 \mu \mathrm{g} / \mathrm{g}$ Stuhl, die interseriellen Variationskoeffizienten bei $7,7 \%$ für die Entscheidungsgrenze $100 \mu \mathrm{g}$ Elastase/g Stuhl und 7,9\% für die Entscheidungsgrenze $200 \mu \mathrm{g} / \mathrm{g}$ Stuhl.

Werte von $<100 \mu \mathrm{g}$ Elastase/g Stuhl zeigen eine schwere exokrine Pankreasinsuffizienz an, Werte zwischen 100 und $200 \mu \mathrm{g}$ eine leichte bis mäßig schwere exokrine Pankreasinsuffizienz und $>200 \mu \mathrm{g}$ eine normale exokrine Pankreasfunktion. Der Test ist linear bis $500 \mu \mathrm{g} / \mathrm{g}$.

\subsubsection{Testprinzip}

Die Vertiefungen der ELISA-Platte sind mit den oben genannten Antikörpern beschichtet. Im ersten Inkubationsschritt werden humane Pankreaselastasemoleküle aus Patientenstuhlproben, aus Kalibratoren (Standards) und Kontrollen durch Antigen-Antikörper-Bindung immobilisiert. Im zweiten Inkubationsschritt werden mit Biotin markierte polyklonale Antikörper zugegeben und an die immobilisierte humane Elastase gebunden. In einem dritten Schritt bindet das Biotin ein Streptavidin-Peroxidase-Konjugat.

Durch die Peroxidase wird das Substrat TMB $\left(3,3^{\prime}, 5,5^{\prime}\right.$-Tetramethylbenzidin) oxidiert; dies führt zu einer blauen Farbreaktion. Die Farbreaktion wird nach einer definierten Zeit (siehe unten) durch die Zugabe von 0,25 molare Schwefelsäure gestoppt, anschließend wird das oxidierte TMB bei $450 \mathrm{~nm}$ fotometrisch bestimmt.

\subsubsection{Durchführung}

Vorbereitungsarbeiten: Bei Aufbewahrung bis $40^{\circ} \mathrm{C}$ können bis zu fünf Tage alte Stuhlproben verwendet werden; im Kühlschrank bei $2-6^{\circ} \mathrm{C}$ blei- 
ben die Proben eine Woche für den Test verwendungsfähig, tief gefroren bei $-18^{\circ} \mathrm{C}$ bis zu einem Jahr.

Die Komponenten und Reagenzien des Kits werden zunächst auf Raumtemperatur $\left(15-30^{\circ} \mathrm{C}\right)$ gebracht.

Danach erfolgt die Herstellung der Extraktionspufferlösung, indem ein Teil des im Kit befindlichen Pufferkonzentrates mit neun Teilen Aqua bidest. verdünnt wird. In gleicher Weise wird der Waschpuffer mit dem Waschpufferkonzentrat hergestellt.

Anschließend erfolgt die Einwaage der Stuhlproben, in dem ein vorher auf einer Feinwaage austariertes Röhrchen mithilfe einer Impföse oder einem Spatel mit etwa 30-100 mg Stuhl befüllt wird. Auf jeweils $1 \mathrm{mg}$ Stuhl wird dann 0,1 ml Extraktionspuffer gegeben.

Die Ansätze werden dann mittels Rotationsschüttler (z. B. Fa. Vortex) 15-30 min durch Schütteln homogenisiert, anschließend werden die festen Bestandteile wiederum 15-30 min sedimentiert und die Überstände abgenommen.

Die je nach Anzahl der Proben benötigte Zahl der Teststreifen mit den Vertiefungen wird entsprechend beschriftet und in einer Halterung befestigt.

Inkubation: Die Stuhlprobenextrakte werden anschließend 1:201 $(1+200$ Teile) mit Waschpuffer verdünnt. Die mitgelieferten Standards sind bereits gebrauchsfertig und brauchen nicht mehr verdünnt zu werden.

Entsprechend einem beigefügten Pipettierschema (siehe unten) werden anschließend jeweils $50 \mu$ l Waschpuffer als "blank" in zwei Vertiefungen gefüllt, ebenso die Standards $1-4$ in jeweils zwei Vertiefungen (Doppelbestimmungen!) sowie in gleicher Weise die Positivkontrollen und die Patientenstuhlproben. Danach erfolgt die Inkubation der Ansätze für 60 min bei Raumtemperatur. 
Die Ansätze werden dann aus den Vertiefungen abgeschüttelt und anschließend $4 \mathrm{x}$ mit jeweils $200 \mu \mathrm{l}$ Waschpuffer gewaschen und der Waschpuffer durch Ausklopfen auf Papiertücher komplett entfernt.

Danach wird der im Testkit enthaltene biotinylierte Anti-Elastase-Antikörper zunächst mit Waschpuffer 1:201 verdünnt (ein Teil biotinylierter Antikörper + 200 Teile Waschpuffer) und davon jeweils $50 \mu \mathrm{l}$ in die Vertiefungen pipettiert und $30 \mathrm{~min}$ bei Raumtemperatur inkubiert. Die Inkubationslösung wird wieder verworfen und anschließend wie im vorigen Schritt wieder $4 \mathrm{x}$ mit Waschpuffer gewaschen und die Pufferreste entfernt. Im nächsten Schritt werden $50 \mu \mathrm{l}$ des beigefügten gebrauchsfertigen Streptavidin-Peroxidase-Konjugates in die Vertiefungen gegeben, anschließend wieder für 30 min bei Raumtemperatur inkubiert, gewaschen und von Pufferresten befreit (wie oben).

Es folgt die Zugabe von jeweils $100 \mu$ l Substratlösung in die Vertiefungen, anschließendes Inkubieren bei Raumtemperatur und in Dunkelheit für 20 min, ab der ersten Substratzugabe gemessen. Nach dieser Zeit wird die enzymatische Reaktion mit jeweils $100 \mu$ Stopplösung pro Vertiefung gestoppt. Das Pipettieren erfolgt in der gleichen Reihenfolge und Geschwindigkeit wie die Zugabe der Substratlösung.

Angewendetes Pipettierschema bei der Testdurchführung:

\begin{tabular}{|c|c|c|c|c|c|c|c|c|c|c|c|c|}
\hline & 1 & 2 & 3 & 4 & 5 & 6 & 7 & 8 & 9 & 10 & 11 & 12 \\
\hline A & Blank & Blank & P 3 & P 3 & P 11 & P 11 & P 19 & P 19 & P 27 & P 27 & P 35 & P 35 \\
\hline B & S 1 & $S 1$ & P 4 & P 4 & P 12 & P 12 & P 20 & P 20 & P 28 & P 28 & P 36 & P 36 \\
\hline C & $S 2$ & $S 2$ & P 5 & P 5 & P 13 & P 13 & P 21 & P 21 & P 29 & P 29 & P 37 & P 37 \\
\hline D & S 3 & S 3 & P 6 & P 6 & P 14 & P 14 & P 22 & P 22 & P 30 & P 30 & P 38 & P 38 \\
\hline $\mathbf{E}$ & S 4 & S 4 & P 7 & P 7 & P 15 & P 15 & P 23 & P 23 & P 31 & P 31 & P 39 & P 39 \\
\hline $\mathbf{F}$ & $K$ & $K$ & P 8 & P 8 & P 16 & P 16 & P 24 & P 24 & P 32 & P 32 & P 40 & P 40 \\
\hline $\mathbf{G}$ & P 1 & P 1 & P 9 & P 9 & P 17 & P 17 & P 25 & P 25 & P 33 & P 33 & P 41 & P 41 \\
\hline H & P 2 & P 2 & P 10 & P 10 & P 18 & P 18 & P 26 & P 26 & P 34 & P 34 & P 42 & P 42 \\
\hline
\end{tabular}

$\mathrm{S}=$ Standard $; \mathrm{K}=$ Kontrolle; $\mathrm{P} 1-\mathrm{P} 42$ = Patientenkontrollen 
Messung: Die Extinktion wird in jeder Vertiefung bei $450 \mathrm{~nm}$ mit einem Mikrotiterplatten-Fotometer bestimmt, wobei die Messung 10 min nach Abstoppen der Farbreaktion erfolgt. Eine Referenzmessung bei $550 \mathrm{~nm}$ Wellenlänge wird ebenfalls durchgeführt.

Auswertung der Ergebnisse: Nach Abzug der Werte der beiden Blanks werden die durchschnittlichen Extinktionswerte für die Standardreihe, die Kontrollen sowie für die Stuhlproben der Patienten errechnet.

Anschließend wird die Extinktion der Standardwerte an die $y$-Achse im Verhältnis zur zugehörigen Konzentration der Elastase an der $\mathrm{x}$-Achse aufgetragen und so eine Standardkurve erzeugt. Den Extinktionen der Patientenstuhlproben werden dann anhand dieser Standardkurve die entsprechenden Patienten-Elastase-Konzentrationen zugeordnet.

Es ist darauf zu achten, dass der Wert der Positivkontrolle zwischen 170 und $230 \mu \mathrm{g} / \mathrm{g}$ liegt, bei Werten darunter oder darüber muss das Kit verworfen und ein neuer Test durchgeführt werden.

\subsubsection{Bewertung}

Zur Beurteilung gelangten nur die Mittelwerte der jeweils drei Bestimmungen mit der jeweiligen Messmethode. Wenn nur ein oder zwei Einzelwerte vorhanden waren, das heißt, der Patient an ein oder zwei Tagen keinen Stuhlgang hatte, wurde trotzdem - wie üblich - der Mittelwert (jeweils geteilt durch 3) berechnet.

Werte von $>200 \mu \mathrm{g}$ Elastase/g Stuhl zeigen eine normale exokrine Pankreasfunktion an und Werte zwischen 100 und $200 \mu \mathrm{g}$ eine leichte bis mäßig schwere exokrine Pankreasinsuffizienz. Bei Werten von $<100 \mu \mathrm{g}$ liegt eine schwere, in der Regel pankreasenzymsubstitutionsbedürftige exokrine Pankreasinsuffizienz vor.

\subsubsection{Stuhlgewichtsbestimmung}

Die Patienten wurden aufgefordert, über 3 aufeinander folgende Tage unter der für sie normalen Ernährung quantitativ ihren Stuhl in 3 Töpfen 
zu sammeln. Die Einzelmengen dieser drei Tagesmengen wurden addiert und anschließend gemittelt. Ein Stuhlgewicht $<200 \mathrm{~g} /$ Tag galt als normal, ein Wert zwischen 200 und $300 \mathrm{~g} / \mathrm{Tag}$ als leichte bis mäßig schwere und ein Stuhlgewicht $>300 \mathrm{~g} / \mathrm{Tag}$ als schwere Diarrhoe (Lankisch et al. 2006).

\subsubsection{Quantitative Stuhlfettanalyse}

Die Bestimmung des Stuhlfettgehaltes erfolgte mittels physikalischer NahInfrarot-Reflexions-Spektrografie (NIRS). Dieses Verfahren ist im Vergleich zu den chemischen Analysen sehr zügig durchführbar (eine Analyse erfolgt in weniger als einer Minute), erfordert nur kleine Stuhlproben und benötigt keine chemischen Reagenzien.

Grundlagen und Bestimmungsprinzip: Die Grundlage der NIRS ist die Tatsache, dass in organischen Molekülen "funktionelle Gruppen", wie zum Beispiel $\mathrm{CH}-, \mathrm{NH}$ - oder $\mathrm{OH}-\mathrm{Gruppen}$ enthalten sind. Diese Molekülgruppen werden durch Bestrahlung mit Infrarotlicht des nahen Infrarotbereiches (ca. 760-2500 nm) angeregt und schwingen. Die einzelnen Gruppen besitzen eine charakteristische Schwingungsfrequenz, wobei es unter anderem zu Oberton- beziehungsweise Kombinationsschwingungen der Grundschwingung im mittleren Infrarotbereich kommt. Werden diese Moleküle also mit Licht einer bestimmten Wellenlänge bestrahlt, die der Schwingungsfrequenz einer bestimmten Gruppe entspricht, so wird ein Teil der Strahlung absorbiert, der übrige Anteil wird reflektiert. Aufgrund der charakteristischen Schwingungsfrequenz und der entsprechenden Absorption hat jede Substanz ein charakteristisches Nahinfrarot-Spektrum und kann auf diese Weise detektiert beziehungsweise quantifiziert werden.

\subsubsection{Durchführung}

Die Analyse der Proben erfolgte mit dem Laborgerät Esetek Analyser Fenir 8820 (Firma Esetek, Rom, Italien). Mit diesem Gerät lassen sich Stuhlproben auf Wasser, Stickstoff und Fett, bei einigen Geräteausführungen zusätzlich auch auf Kohlenhydrate, untersuchen. Der Stuhl wird auf spe- 
zielle, weitgehend luftdicht abgeschlossene Petrischalen aus Glas gegeben, welche gleichzeitig auch zur (geruchsfreien) Aufbewahrung der Proben und damit gegebenenfalls zur Reproduktion der Ergebnisse dienen können. Zur Verbesserung des Bedienungskomforts ist das Gerät im Pankreaslabor der Universitätsmedizin Göttingen mit einem Computer verbunden.

Der Stuhl wird vorher durch Rühren ohne Verdünnung homogenisiert und so in die Schalen gegeben, dass der gesamte Schalenboden bedeckt ist; ein Einwiegen der Stuhlmenge ist nicht notwendig. Die Schale mit der Stuhlprobe wird mit einem entsprechenden Glasdeckel verschlossen und in eine am Gerät vorhandene, nach unten teilweise offene Vertiefung eingelegt, unter der sich die Infrarotbeleuchtungs- und Messeinrichtung befindet. Die Analyse erfolgt also direkt von unten durch den Boden des Probenbehälters hindurch. Die Fläche der Petrischale wird durch automatische Vorschaltung entsprechender Filter mit Licht zwischen 1400 und $2500 \mathrm{~nm}$ bestrahlt und die Reflexion in einem Kugelspiegel gemessen. Für die Analyse von Stuhlfett ist die Frequenz der $\mathrm{CH}-G r u p p e n$ entscheidend, deren Absorptionseigenschaften verwendet werden.

Ein im Gerät integrierter Mikroprozessor vergleicht und errechnet simultan und vollautomatisch die reflektierte Energie der einzelnen Wellenlängen mit entsprechend gespeicherten Daten. Die Messung wird mittels Mausklick gestartet, das Ergebnis erscheint nach ca. $30 \mathrm{sec}$ auf einem mit dem Gerät verbundenen Monitor in $\mathrm{g}$ Fett/100 g Stuhl. Dieser Wert wird dann mit dem gesammelten Tagesstuhlgewicht verrechnet und so der Stuhlfettgehalt pro Tag ermittelt.

\subsubsection{Bewertung}

Ein täglicher Stuhlfettgehalt von $<7 \mathrm{~g}$ gilt als normal. Bei Werten zwischen 7 und $15 \mathrm{~g}$ liegt eine leichte bis mäßig schwere Steatorrhoe, also eine nicht substitutionsbedürftige Stuhlfetterhöhung vor. Eine Stuhlfettausscheidung von $>15 \mathrm{~g} /$ Tag gilt als schwere Steatorrhoe. In diesem Fall 
werden in den Leitlinien zur Therapie der chronischen Pankreatitis der Gesellschaft für Verdauungs- und Stoffwechselkrankheiten (Mössner et al. 1998) Pankreasenzyme zur Behandlung einer pankreatogenen Steatorrhoe empfohlen.

\subsection{Statistik}

Zur statistischen Auswertung wurden „Fishers exakter Test" und der „Mantel-Haenszel-Test" für eine Trendanalyse, wie in den Tabellen angegeben, angewendet.

\subsection{Ethik-Votum}

Die Studie war von dem Ethik-Komitee der Georg-August-Universität unter der Nr. 6/3/08 genehmigt worden. 


\section{Ergebnisse}

\subsection{Demografische Angaben der Patienten}

Die Mehrheit der untersuchten Patienten war männlichen Geschlechts $(n=30,60 \%)$ (Tabelle 1$)$.

Das Durchschnittsalter der Patienten betrug $57 \pm 15$ (20-83) Jahre. Das Alter der 20 Patientinnen lag mit $59 \pm 13$ (34-80) Jahren leicht über dem der 30 Männer mit $56 \pm 15$ (20-83) Jahren. Die Anzahl der Patienten waren nahezu gleichmäßig auf alle Altersklassen verteilt (Tabelle 1).

Etwas mehr als ein Drittel der Patienten $(n=19,38 \%)$ war normalgewichtig. Nur zwei von innen waren mit einem Body Mass Index (BMI) von 19 $\mathrm{kg} / \mathrm{m}^{2}$ (Patientin 4, Patient 17; Tabelle 2) leicht untergewichtig, wurden aber trotzdem in die Normalgewichtsklasse aufgenommen. Bei 19 (38\%) der Patienten bestand Übergewicht, 12 (24\%) waren adipös (Tabelle 1).

Im Durchschnitt hatten die 50 Patienten ein leichtes Übergewicht (BMI 27 $\pm 6(19-51) \mathrm{kg} / \mathrm{m}^{2}$. Der durchschnittliche BMI lag bei Frauen mit $27 \pm 8$ $(19-51) \mathrm{kg} / \mathrm{m}^{2}$ leicht über dem der Männer mit $26 \pm 4(19-35) \mathrm{kg} / \mathrm{m}^{2}$. Immerhin 31 (62\%) Patienten hatten entweder ein Übergewicht oder eine Adipositas 1. Grades (Tabelle 1).

Die durchschnittliche Dialysedauer der 50 Patienten betrug $36 \pm 34$ (1169) Monate; Männer waren mit $35 \pm 39$ (4-169) Monaten länger als Frauen mit $22 \pm 21(1-71)$ Monaten dialysiert worden. Fast zwei Drittel (68\%) der Patienten war zum Zeitpunkt der Pankreasfunktionsprüfung mehr als 1 Jahr lang dialysiert worden (Tabelle 1).

Bei den Ursachen der terminalen Niereninsuffizienz überwogen die hypertensive und die autoimmune Nephropathie, gefolgt von der diabetischen, der hereditären und den sonstigen Nephropathien (Tabelle 1). 
Tabelle 1

Demografische Angaben zu den 50 untersuchten Hämodialyse-Patienten

\begin{tabular}{|c|c|}
\hline Parameter & $\mathrm{n}(\%)$ \\
\hline \multicolumn{2}{|l|}{ Geschlecht } \\
\hline Männer & $30(60)$ \\
\hline Frauen & $20(40)$ \\
\hline \multicolumn{2}{|l|}{ Alter (Jahre) } \\
\hline $0<50$ & $13(26)$ \\
\hline$\circ \quad 50-59$ & $12(24)$ \\
\hline$\circ 60-69$ & $13(26)$ \\
\hline$\circ \quad \geq 70$ & $12(24)$ \\
\hline \multicolumn{2}{|c|}{ Body Mass I ndex (BMI ) $\left(\mathrm{kg} / \mathrm{m}^{2}\right)$} \\
\hline$\circ \quad<25$ & $19(38)$ \\
\hline ○ $25-29$ & $19(38)$ \\
\hline$\circ \quad \geq 30$ & $12(24)$ \\
\hline \multicolumn{2}{|c|}{$\begin{array}{l}\text { Ursache der terminalen Niereninsuffizienz } \\
\text { (Diagnoseklassen) }\end{array}$} \\
\hline ○ Hypertensiv & $14(28)$ \\
\hline ○ Diabetisch & $10(20)$ \\
\hline ○ Hereditär & $8(16)$ \\
\hline$\circ$ Autoimmun & $13(26)$ \\
\hline$\circ$ Sonstige & $5(10)$ \\
\hline \multicolumn{2}{|c|}{ Dauer der Dialyse (Monate) } \\
\hline$<12$ & $16(32)$ \\
\hline$\circ \quad 12-24$ & $12(24)$ \\
\hline$\circ \quad 25-36$ & $5(10)$ \\
\hline$>36$ & $17(34)$ \\
\hline
\end{tabular}


Tabelle 2. Geschlecht, Alter und BMI, die Dialysedauer und Diagnoseklasse (1: hypertensive Nephropathie; 2: diabetische Nephropathie; 3: hereditäre Nephropathie; 4: Autoimmunnephropathie; 5: sonstige Nephropathien) der Patienten und folgende bei ihnen gemessene Parameter: Stuhlgewicht, Stuhlfett sowie Elastase 1 im Stuhl (pathologische Werte eingekastelt).

\begin{tabular}{|c|c|c|c|c|c|c|c|c|c|c|c|}
\hline \multirow{2}{*}{$\begin{array}{l}\text { Patientendaten } \\
\\
\text { Nr./Initialen/ } \\
\text { Geschlecht/Alter }\end{array}$} & \multirow[t]{2}{*}{ BMI } & \multirow{2}{*}{$\begin{array}{l}\text { Dialyse- } \\
\text { dauer } \\
\text { (Monate) }\end{array}$} & \multirow{2}{*}{$\begin{array}{l}\text { Diag- } \\
\text { nose- } \\
\text { klasse } \\
\text { (siehe } \\
\text { Über- } \\
\text { schrift) }\end{array}$} & \multicolumn{2}{|c|}{$\begin{array}{c}\text { Stuhlgewicht } \\
\text { (normal }<200 \mathrm{~g} / \mathrm{Tag} \text { ) }\end{array}$} & \multicolumn{2}{|c|}{$\begin{array}{c}\text { Stuhlfett } \\
\text { (normal }<7 \mathrm{~g} / \mathrm{Tag} \text { ) }\end{array}$} & \multicolumn{4}{|c|}{ Elastase 1 (normal > $200 \mu \mathrm{g} / \mathrm{g}$ Stuhl) } \\
\hline & & & & g/Tag & $\begin{array}{l}\text { Mittelwert } \\
\text { g/Tag }\end{array}$ & g/Tag & $\begin{array}{l}\text { Mittelwert } \\
\text { g/Tag }\end{array}$ & $\begin{array}{c}\text { Methode } \\
\text { Bioserv } \\
\text { Diagnostics } \\
\mu \mathrm{g} / \mathrm{g} \text { Stuhl }\end{array}$ & $\begin{array}{c}\text { Mittel- } \\
\text { wert } \\
\mu \mathrm{g} / \mathrm{g} \\
\text { Stuhl }\end{array}$ & $\begin{array}{c}\text { Methode } \\
\text { ScheBo- } \\
\text { Biotech } \\
\mu \mathrm{g} / \mathrm{g} \text { Stuhl }\end{array}$ & $\begin{array}{c}\text { Mittel- } \\
\text { wert } \\
\mu \mathrm{g} / \mathrm{g} \\
\text { Stuhl }\end{array}$ \\
\hline $\begin{array}{l}\text { 1. F.K. } \sigma^{\top} \\
61 \text { Jahre }\end{array}$ & 27 & 5 & 1 & \begin{tabular}{|l|}
252 \\
274 \\
232 \\
\end{tabular} & 255 & $\begin{array}{l}8,3 \\
9,6 \\
8,7\end{array}$ & 8,9 & $\begin{array}{l}346 \\
220 \\
285\end{array}$ & 284 & \begin{tabular}{|l|}
141 \\
112 \\
228 \\
\end{tabular} & 160 \\
\hline $\begin{array}{l}\text { 2. E.G. } \stackrel{+}{ } \\
60 \text { Jahre }\end{array}$ & 29 & 71 & 2 & $\begin{array}{l}49 \\
60 \\
80\end{array}$ & 63 & $\begin{array}{l}2,5 \\
2,6 \\
2,3\end{array}$ & 2,5 & $\begin{array}{c}>500 \\
442 \\
427\end{array}$ & 456 & $\begin{array}{l}420 \\
315 \\
408\end{array}$ & 381 \\
\hline $\begin{array}{l}\text { 3. T.S. } \sigma^{\pi} \\
20 \text { Jahre }\end{array}$ & 24 & 36 & 3 & $\begin{array}{r}51 \\
0 \\
30 \\
\end{array}$ & 27 & $\begin{array}{c}1,3 \\
0 \\
*) \\
\end{array}$ & 0,4 & $\begin{array}{l}>500 \\
>500\end{array}$ & $>500$ & $\begin{array}{l}>500 \\
>500\end{array}$ & $>500$ \\
\hline $\begin{array}{l}\text { 4. N.A. } \stackrel{+}{ } \\
38 \text { Jahre }\end{array}$ & 19 & 24 & 1 & $\begin{array}{r}31 \\
0 \\
0\end{array}$ & 10 & $\begin{array}{c}1,1 \\
0 \\
0\end{array}$ & 0,4 & 490 & 490 & 380 & 380 \\
\hline $\begin{array}{l}\text { 5. H.S. O } \\
53 \text { Jahre }\end{array}$ & 28 & 15 & 1 & $\begin{array}{r}150 \\
56 \\
95\end{array}$ & 100 & \begin{tabular}{|c|}
10,0 \\
4,9 \\
5,0 \\
\end{tabular} & 6,6 & $\begin{array}{l}207 \\
287 \\
270\end{array}$ & 255 & $\begin{array}{l}212 \\
360 \\
150\end{array}$ & 241 \\
\hline $\begin{array}{l}\text { 6. I.M. } \stackrel{+}{ } \\
45 \text { Jahre }\end{array}$ & 33 & 36 & 2 & $\begin{array}{l}110 \\
245 \\
200\end{array}$ & 185 & $\begin{array}{l}5,7 \\
9,2 \\
4,1\end{array}$ & 6,3 & $\begin{array}{l}490 \\
450 \\
425\end{array}$ & 456 & $\begin{array}{l}300 \\
300 \\
260\end{array}$ & 287 \\
\hline $\begin{array}{l}\text { 7. H.P. } \stackrel{+}{ } \\
50 \text { Jahre }\end{array}$ & 29 & 12 & 1 & $\begin{array}{r}90 \\
181 \\
186\end{array}$ & 152 & $\begin{array}{l}3,1 \\
7,6 \\
5,7\end{array}$ & 5,4 & $\begin{array}{l}490 \\
465 \\
480\end{array}$ & 478 & $\begin{array}{l}320 \\
365 \\
320\end{array}$ & 335 \\
\hline $\begin{array}{l}\text { 8. C.N. O } \\
54 \text { Jahre }\end{array}$ & 27 & 43 & 4 & \begin{tabular}{|l|}
160 \\
320 \\
300 \\
\end{tabular} & 260 & $\begin{array}{l}6,0 \\
9,2 \\
6,8 \\
\end{array}$ & 7,3 & $\begin{array}{l}460 \\
430 \\
420\end{array}$ & 437 & $\begin{array}{l}396 \\
340 \\
275\end{array}$ & 337 \\
\hline
\end{tabular}




\begin{tabular}{|c|c|c|c|c|c|c|c|c|c|c|c|}
\hline \multirow{2}{*}{$\begin{array}{l}\text { Patientendaten } \\
\\
\text { Nr./Initialen/ } \\
\text { Geschlecht/Alter }\end{array}$} & \multirow[t]{2}{*}{ BMI } & \multirow{2}{*}{$\begin{array}{l}\text { Dialyse- } \\
\text { dauer } \\
\text { (Monate) }\end{array}$} & \multirow{2}{*}{$\begin{array}{l}\text { Diag- } \\
\text { nose- } \\
\text { klasse } \\
\text { (siehe } \\
\text { Über- } \\
\text { schrift) }\end{array}$} & \multicolumn{2}{|c|}{$\begin{array}{c}\text { Stuhlgewicht } \\
\text { (normal <200 g/Tag) }\end{array}$} & \multicolumn{2}{|c|}{$\begin{array}{c}\text { Stuhlfett } \\
\text { (normal }<7 \mathrm{~g} / T a g \text { ) }\end{array}$} & \multicolumn{4}{|c|}{ Elastase 1 (normal >200 $\mu \mathrm{g} / \mathrm{g}$ Stuhl) } \\
\hline & & & & $\mathrm{g} / \mathrm{Tag}$ & $\begin{array}{l}\text { Mittelwert } \\
\text { g/Tag }\end{array}$ & $\mathrm{g} / \mathrm{Tag}$ & $\begin{array}{l}\text { Mittelwert } \\
\text { g/Tag }\end{array}$ & $\begin{array}{l}\text { Methode } \\
\text { Bioserv } \\
\text { Diagnostics } \\
\mu \mathrm{g} / \mathrm{g} \text { Stuhl }\end{array}$ & $\begin{array}{l}\text { Mittel- } \\
\text { wert } \\
\mu \mathrm{g} / \mathrm{g} \\
\text { Stuhl }\end{array}$ & $\begin{array}{c}\text { Methode } \\
\text { ScheBo- } \\
\text { Biotech } \\
\mu \mathrm{g} / \mathrm{g} \text { Stuhl }\end{array}$ & $\begin{array}{c}\text { Mittel- } \\
\text { wert } \\
\mu \mathrm{g} / \mathrm{g} \\
\text { Stuhl }\end{array}$ \\
\hline $\begin{array}{l}\text { 9. M.S. } 0^{\pi} \\
54 \text { Jahre }\end{array}$ & 29 & 64 & 4 & $\begin{array}{r}288 \\
161 \\
0\end{array}$ & 150 & \begin{tabular}{|c|}
14,3 \\
8,0 \\
0
\end{tabular} & 7,4 & $\begin{array}{l}490 \\
485\end{array}$ & 488 & $\begin{array}{l}315 \\
355\end{array}$ & 335 \\
\hline $\begin{array}{l}\text { 10. E.S. } 0^{\pi} \\
60 \text { Jahre }\end{array}$ & 27 & 20 & 4 & $\begin{array}{r}141 \\
54 \\
84 \\
\end{array}$ & 93 & $\begin{array}{l}9,0 \\
3,6 \\
3,7\end{array}$ & 5,4 & $\begin{array}{l}458 \\
475 \\
400 \\
\end{array}$ & 444 & $\begin{array}{l}260 \\
240 \\
260\end{array}$ & 253 \\
\hline $\begin{array}{l}\text { 11. H.W. } \stackrel{+}{ } \\
62 \text { Jahre }\end{array}$ & 24 & 18 & 3 & $\begin{array}{r}172 \\
68 \\
118\end{array}$ & 120 & $\begin{array}{l}3,4 \\
1,5 \\
3,9\end{array}$ & 2,9 & $\begin{array}{l}420 \\
400 \\
485 \\
\end{array}$ & 435 & $\begin{array}{l}400 \\
440 \\
440 \\
\end{array}$ & 427 \\
\hline $\begin{array}{l}\text { 12. U.W. ㅇ } \\
34 \text { Jahre }\end{array}$ & 23 & 45 & 3 & $\begin{array}{l}127 \\
\frac{262}{145}\end{array}$ & 180 & $\begin{array}{c}5,6 \\
\frac{12,2}{5,5}\end{array}$ & 7,8 & $\begin{array}{l}440 \\
395 \\
388\end{array}$ & 408 & $\begin{array}{l}290 \\
268 \\
250\end{array}$ & 269 \\
\hline $\begin{array}{l}\text { 13. U.S. 우 } \\
64 \text { Jahre }\end{array}$ & 20 & 3 & 1 & $\begin{array}{r}110 \\
96 \\
290 \\
\end{array}$ & 165 & $\begin{array}{l}2,3 \\
2,4 \\
3,4\end{array}$ & 2,7 & $\begin{array}{c}410 \\
>500 \\
455 \\
\end{array}$ & 455 & $\begin{array}{l}460 \\
465 \\
460 \\
\end{array}$ & 462 \\
\hline $\begin{array}{l}\text { 14. K.E. } 0^{\pi} \\
38 \text { Jahre }\end{array}$ & 21 & 5 & 1 & $\begin{array}{r}126 \\
89 \\
73\end{array}$ & 96 & $\begin{array}{l}3,4 \\
2,2 \\
2,1\end{array}$ & 2,6 & $\begin{array}{c}>500 \\
>500 \\
450\end{array}$ & 483 & $\begin{array}{l}>500 \\
>500 \\
>500\end{array}$ & $>500$ \\
\hline $\begin{array}{l}\text { 15. U.R. ㅇ } \\
55 \text { Jahre }\end{array}$ & 39 & 7 & 2 & $\begin{array}{r}88 \\
196 \\
52 \\
\end{array}$ & 112 & \begin{tabular}{c|}
8,3 \\
11,7 \\
4,1 \\
\end{tabular} & 8,0 & $\begin{array}{l}>500 \\
>500 \\
>500 \\
\end{array}$ & $>500$ & $\begin{array}{l}390 \\
336 \\
426 \\
\end{array}$ & 384 \\
\hline $\begin{array}{l}\text { 16. M.B. } 0^{\top} \\
48 \text { Jahre }\end{array}$ & 21 & 11 & 5 & $\begin{array}{r}98 \\
216 \\
171 \\
\end{array}$ & 162 & $\begin{array}{c}5,2 \\
10,7 \\
9,0\end{array}$ & 8,3 & $\begin{array}{l}297 \\
201 \\
200\end{array}$ & 233 & $\begin{array}{l}260 \\
247 \\
335\end{array}$ & 281 \\
\hline
\end{tabular}




\begin{tabular}{|c|c|c|c|c|c|c|c|c|c|c|c|}
\hline \multirow{2}{*}{$\begin{array}{l}\text { Patientendaten } \\
\\
\text { Nr./Initialen/ } \\
\text { Geschlecht/Alter }\end{array}$} & \multirow[t]{2}{*}{ BMI } & \multirow{2}{*}{$\begin{array}{l}\text { Dialyse- } \\
\text { dauer } \\
\text { (Monate) }\end{array}$} & \multirow{2}{*}{$\begin{array}{l}\text { Diag- } \\
\text { nose- } \\
\text { klasse } \\
\text { (siehe } \\
\text { Über- } \\
\text { schrift) }\end{array}$} & \multicolumn{2}{|c|}{$\begin{array}{c}\text { Stuhlgewicht } \\
\text { (normal }<200 \mathrm{~g} / \mathrm{Tag} \text { ) }\end{array}$} & \multicolumn{2}{|c|}{$\begin{array}{c}\text { Stuhlfett } \\
\text { (normal }<7 \mathrm{~g} / \mathrm{Tag} \text { ) }\end{array}$} & \multicolumn{4}{|c|}{ Elastase 1 (normal > $200 \mu \mathrm{g} / \mathrm{g}$ Stuhl) } \\
\hline & & & & g/Tag & $\begin{array}{l}\text { Mittelwert } \\
\text { g/Tag }\end{array}$ & $\mathrm{g} / \mathrm{Tag}$ & $\begin{array}{l}\text { Mittelwert } \\
\text { g/Tag }\end{array}$ & $\begin{array}{c}\text { Methode } \\
\text { Bioserv } \\
\text { Diagnostics } \\
\mu \mathrm{g} / \mathrm{g} \text { Stuhl }\end{array}$ & $\begin{array}{c}\text { Mittel- } \\
\text { wert } \\
\mu \mathrm{g} / \mathrm{g} \\
\text { Stuhl }\end{array}$ & $\begin{array}{c}\text { Methode } \\
\text { ScheBo- } \\
\text { Biotech } \\
\mu \mathrm{g} / \mathrm{g} \text { Stuhl }\end{array}$ & $\begin{array}{c}\text { Mittel- } \\
\text { wert } \\
\mu \mathrm{g} / \mathrm{g} \\
\text { Stuhl }\end{array}$ \\
\hline $\begin{array}{l}\text { 17. M.K. } \sigma^{\top} \\
32 \text { Jahre }\end{array}$ & 19 & 55 & 5 & $\begin{array}{r}120 \\
52 \\
0\end{array}$ & 57 & $\begin{array}{c}11,6 \\
2,0 \\
0\end{array}$ & 4,5 & $\begin{array}{l}300 \\
208\end{array}$ & 254 & $\begin{array}{l}312 \\
212\end{array}$ & 262 \\
\hline $\begin{array}{l}\text { 18. H.D. ठð } \\
56 \text { Jahre }\end{array}$ & 26 & 4 & 1 & $\begin{array}{l}380 \\
180 \\
165\end{array}$ & 240 & $\begin{array}{l}5,1 \\
3,5 \\
3,0\end{array}$ & 3,9 & $\begin{array}{l}345 \\
400 \\
404\end{array}$ & 383 & $\begin{array}{l}294 \\
416 \\
400\end{array}$ & 370 \\
\hline $\begin{array}{l}\text { 19. W.D. } \sigma^{\pi} \\
66 \text { Jahre }\end{array}$ & 27 & 49 & 1 & $\begin{array}{r}56 \\
102 \\
0\end{array}$ & 53 & $\begin{array}{c}7,5 \\
7,7 \\
0\end{array}$ & 5,1 & $\begin{array}{l}>500 \\
>500\end{array}$ & $>500$ & $\begin{array}{l}445 \\
445\end{array}$ & 445 \\
\hline $\begin{array}{l}\text { 20. B.K. } 0^{\pi} \\
54 \text { Jahre }\end{array}$ & 31 & 169 & 4 & $\begin{array}{r}163 \\
92 \\
128\end{array}$ & 128 & $\begin{array}{c}10,5 \\
5,3 \\
6,6\end{array}$ & 7,5 & $\begin{array}{l}460 \\
437 \\
410\end{array}$ & 436 & $\begin{array}{l}495 \\
490 \\
490\end{array}$ & 492 \\
\hline $\begin{array}{l}\text { 21. W.F. } \sigma^{\top} \\
60 \text { Jahre }\end{array}$ & 27 & 20 & 3 & $\begin{array}{r}44 \\
177 \\
102 \\
\end{array}$ & 108 & $\begin{array}{l}2,4 \\
6,5 \\
4,9\end{array}$ & 4,6 & $\begin{array}{l}>500 \\
>500 \\
>500\end{array}$ & $>500$ & $\begin{array}{l}424 \\
365 \\
488 \\
\end{array}$ & 426 \\
\hline $\begin{array}{l}\text { 22. B.S. 우 } \\
51 \text { Jahre }\end{array}$ & 31 & 54 & 2 & $\begin{array}{l}170 \\
160 \\
217\end{array}$ & 182 & $\begin{array}{l}3,9 \\
3,4 \\
4,1\end{array}$ & 3,8 & $\begin{array}{l}366 \\
342 \\
330\end{array}$ & 346 & $\begin{array}{l}>500 \\
>500 \\
>500\end{array}$ & $>500$ \\
\hline $\begin{array}{l}\text { 23. H.Dr. }{ }^{\star} \\
56 \text { Jahre }\end{array}$ & 23 & 156 & 4 & $\begin{array}{r}54 \\
0 \\
106 \\
\end{array}$ & 55 & $\begin{array}{c}1,3 \\
0 \\
2,6 \\
\end{array}$ & 1,2 & $\begin{array}{l}450 \\
425 \\
\end{array}$ & 438 & $\begin{array}{r}494 \\
498 \\
\end{array}$ & 496 \\
\hline $\begin{array}{l}\text { 24. M.M. } \stackrel{+}{ } \\
48 \text { Jahre }\end{array}$ & 51 & 4 & 2 & $\begin{array}{r}0 \\
0 \\
105\end{array}$ & 35 & $\begin{array}{c}0 \\
0 \\
7,2\end{array}$ & 2,4 & 445 & 445 & 310 & 310 \\
\hline
\end{tabular}




\begin{tabular}{|c|c|c|c|c|c|c|c|c|c|c|c|}
\hline \multirow{2}{*}{$\begin{array}{l}\text { Patientendaten } \\
\text { Nr./Initialen/ } \\
\text { Geschlecht/Alter }\end{array}$} & \multirow[t]{2}{*}{ BMI } & \multirow{2}{*}{$\begin{array}{l}\begin{array}{c}\text { Dialyse- } \\
\text { dauer }\end{array} \\
\text { (Monate) }\end{array}$} & \multirow{2}{*}{$\begin{array}{l}\text { Diag- } \\
\text { nose- } \\
\text { klasse } \\
\text { (siehe } \\
\text { Über- } \\
\text { schrift) }\end{array}$} & \multicolumn{2}{|c|}{$\begin{array}{c}\text { Stuhlgewicht } \\
\text { (normal <200 g/Tag) }\end{array}$} & \multicolumn{2}{|c|}{$\begin{array}{c}\text { Stuhlfett } \\
\text { (normal }<7 \mathrm{~g} / \mathrm{Tag})\end{array}$} & \multicolumn{4}{|c|}{ Elastase 1 (normal $>200 \mu \mathrm{g} / \mathrm{g}$ Stuhl) } \\
\hline & & & & $\mathrm{g} / \mathrm{Tag}$ & $\begin{array}{l}\text { Mittelwert } \\
\text { g/Tag }\end{array}$ & $\mathrm{g} / \mathrm{Tag}$ & $\begin{array}{l}\text { Mittelwert } \\
\text { g/Tag }\end{array}$ & $\begin{array}{l}\text { Methode } \\
\text { Bioserv } \\
\text { Diagnostics } \\
\mu \mathrm{g} / \mathrm{g} \text { Stuhl }\end{array}$ & $\begin{array}{c}\text { Mittel- } \\
\text { wert } \\
\mu \mathrm{g} / \mathrm{g} \\
\text { Stuhl }\end{array}$ & $\begin{array}{c}\text { Methode } \\
\text { ScheBo- } \\
\text { Biotech } \\
\mu \mathrm{g} / \mathrm{g} \text { Stuhl }\end{array}$ & $\begin{array}{c}\text { Mittel- } \\
\text { wert } \\
\mu \mathrm{g} / \mathrm{g} \\
\text { Stuhl }\end{array}$ \\
\hline $\begin{array}{l}\text { 25. K.G. } \sigma^{\top} \\
52 \text { Jahre }\end{array}$ & 21 & 5 & 4 & $\begin{array}{r}182 \\
56 \\
155\end{array}$ & 131 & $\begin{array}{l}2,1 \\
0,6 \\
4,3\end{array}$ & 2,3 & \begin{tabular}{|l|}
125 \\
$<50$ \\
220
\end{tabular} & 132 & \begin{tabular}{|l|}
$\frac{120}{120}$ \\
300
\end{tabular} & 180 \\
\hline $\begin{array}{l}\text { 26. E.Go. } 0^{\pi} \\
64 \text { Jahre }\end{array}$ & 27 & 25 & 5 & \begin{tabular}{l|}
166 \\
271 \\
174
\end{tabular} & 205 & \begin{tabular}{|l|}
14,0 \\
16,3 \\
12,3 \\
\end{tabular} & 14,2 & $\begin{array}{c}>500 \\
450 \\
>500\end{array}$ & 483 & $\begin{array}{l}397 \\
380 \\
411\end{array}$ & 396 \\
\hline $\begin{array}{l}\text { 27. B.Kö. } 0^{\pi} \\
63 \text { Jahre }\end{array}$ & 25 & 16 & 4 & $\begin{array}{l}298 \\
159 \\
383 \\
\end{array}$ & 280 & \begin{tabular}{|l}
13,5 \\
5,0 \\
12,5
\end{tabular} & 10,3 & $\begin{array}{l}278 \\
188 \\
230\end{array}$ & 232 & \begin{tabular}{|l|}
127 \\
135 \\
140 \\
\end{tabular} & 134 \\
\hline $\begin{array}{l}\text { 28. E.B. ㅇ } \\
58 \text { Jahre }\end{array}$ & 31 & 63 & 4 & \begin{tabular}{|l|}
171 \\
234 \\
236
\end{tabular} & 214 & $\begin{array}{l}4,5 \\
6,7 \\
3,6\end{array}$ & 4,9 & \begin{tabular}{|l|}
$\frac{150}{160}$ \\
222
\end{tabular} & 177 & $\begin{array}{l}210 \\
210 \\
287\end{array}$ & 236 \\
\hline $\begin{array}{l}\text { 29. V.T. } 0^{\pi} \\
53 \text { Jahre }\end{array}$ & 35 & 5 & 1 & \begin{tabular}{|l|}
238 \\
175 \\
202 \\
\end{tabular} & 205 & $\frac{9,6}{\frac{9,6}{10,4}}$ & 9,1 & $\begin{array}{l}>500 \\
>500 \\
>500\end{array}$ & $>500$ & $\begin{array}{l}400 \\
437 \\
470\end{array}$ & 436 \\
\hline $\begin{array}{l}\text { 30. A.F. ㅇ } \\
42 \text { Jahre }\end{array}$ & 45 & 1 & 4 & \begin{tabular}{|l|}
386 \\
155 \\
286
\end{tabular} & 275 & $\begin{array}{l}5,5 \\
4,2 \\
4,2\end{array}$ & 4,6 & \begin{tabular}{|l}
160 \\
222 \\
300
\end{tabular} & 227 & $\begin{array}{l}230 \\
236 \\
263\end{array}$ & 243 \\
\hline $\begin{array}{l}\text { 31. S.H. } \sigma^{\nwarrow} \\
23 \text { Jahre }\end{array}$ & 21 & 53 & 3 & $\begin{array}{r}144 \\
110 \\
0\end{array}$ & 85 & $\begin{array}{c}4,9 \\
3,0 \\
0\end{array}$ & 2,6 & $\begin{array}{l}430 \\
490\end{array}$ & 460 & $\begin{array}{l}470 \\
495\end{array}$ & 483 \\
\hline $\begin{array}{l}\text { 32. D.S. ㅇ } \\
65 \text { Jahre }\end{array}$ & 33 & 13 & 2 & $\begin{array}{r}86 \\
141 \\
0 \\
\end{array}$ & 76 & $\begin{array}{c}4,3 \\
7,0 \\
0\end{array}$ & 3,8 & $\begin{array}{l}485 \\
435\end{array}$ & 460 & $\begin{array}{l}370 \\
370\end{array}$ & 370 \\
\hline
\end{tabular}




\begin{tabular}{|c|c|c|c|c|c|c|c|c|c|c|c|}
\hline \multirow{2}{*}{$\begin{array}{l}\text { Patientendaten } \\
\text { Nr./Initialen/ } \\
\text { Geschlecht/Alter }\end{array}$} & \multirow[t]{2}{*}{ BMI } & \multirow{2}{*}{$\begin{array}{l}\text { Dialyse- } \\
\text { dauer }\end{array}$} & \multirow{2}{*}{$\begin{array}{l}\text { Diag- } \\
\text { nose- } \\
\text { klasse } \\
\text { (siehe } \\
\text { Über- } \\
\text { schrift) }\end{array}$} & \multicolumn{2}{|c|}{$\begin{array}{c}\text { Stuhlgewicht } \\
\text { (normal }<200 \mathrm{~g} / \mathrm{Tag})\end{array}$} & \multicolumn{2}{|c|}{$\begin{array}{c}\text { Stuhlfett } \\
\text { (normal }<7 \mathrm{~g} / \mathrm{Tag} \text { ) }\end{array}$} & \multicolumn{4}{|c|}{ Elastase 1 (normal >200 $\mu \mathrm{g} / \mathrm{g}$ Stuhl) } \\
\hline & & & & $\mathrm{g} / \mathrm{Tag}$ & $\begin{array}{c}\text { Mittelwert } \\
\text { g/Tag }\end{array}$ & g/Tag & $\begin{array}{l}\text { Mittelwert } \\
\text { g/Tag }\end{array}$ & $\begin{array}{l}\text { Methode } \\
\text { Bioserv } \\
\text { Diagnostics } \\
\mu \mathrm{g} / \mathrm{g} \text { Stuhl }\end{array}$ & $\begin{array}{l}\text { Mittel- } \\
\text { wert } \\
\mu g / g \\
\text { Stuhl }\end{array}$ & $\begin{array}{c}\text { Methode } \\
\text { ScheBo- } \\
\text { Biotech } \\
\mu \mathrm{g} / \mathrm{g} \text { Stuhl }\end{array}$ & $\begin{array}{c}\text { Mittel- } \\
\text { wert } \\
\mu \mathrm{g} / \mathrm{g} \\
\text { Stuhl }\end{array}$ \\
\hline $\begin{array}{l}\text { 33. E.Bi. 우 } \\
80 \text { Jahre }\end{array}$ & 23 & 45 & 4 & $\begin{array}{r}0 \\
178 \\
0\end{array}$ & 59 & $\begin{array}{c}0 \\
\frac{12,7}{0}\end{array}$ & 4,2 & $>500$ & $>500$ & 490 & 490 \\
\hline $\begin{array}{l}\text { 34. A.K. }{ }^{\pi} \\
76 \text { Jahre }\end{array}$ & 24 & 23 & 1 & $\begin{array}{r}64 \\
144 \\
85\end{array}$ & 98 & $\begin{array}{l}4,3 \\
7,4 \\
6,7\end{array}$ & 6,1 & $\begin{array}{l}450 \\
413 \\
360\end{array}$ & 408 & $\begin{array}{l}310 \\
300 \\
230\end{array}$ & 280 \\
\hline $\begin{array}{l}\text { 35. W.T. o } \\
72 \text { Jahre }\end{array}$ & 31 & 40 & 2 & $\begin{array}{r}176 \\
133 \\
10 \\
\end{array}$ & 106 & $\begin{array}{l}6,4 \\
4,6 \\
*)\end{array}$ & 3,7 & $\begin{array}{l}317 \\
334 \\
220\end{array}$ & 290 & \begin{tabular}{|l|}
156 \\
153 \\
102 \\
\end{tabular} & 137 \\
\hline $\begin{array}{l}\text { 36. H.B. }+9 \\
71 \text { Jahre }\end{array}$ & 24 & 21 & 1 & $\begin{array}{r}30 \\
187 \\
198\end{array}$ & 138 & $\begin{array}{l}1,1 \\
2,9 \\
1,1\end{array}$ & 1,7 & $\begin{array}{l}390 \\
350 \\
325\end{array}$ & 355 & $\begin{array}{l}>500 \\
>500 \\
>500\end{array}$ & $>500$ \\
\hline $\begin{array}{l}\text { 37. C.T. 우 } \\
78 \text { Jahre }\end{array}$ & 26 & 7 & 1 & $\begin{array}{r}19 \\
0 \\
52 \\
\end{array}$ & 24 & $\begin{array}{c}1,2 \\
0 \\
3 \\
\end{array}$ & 1,4 & $\begin{array}{l}>500 \\
>500 \\
\end{array}$ & $>500$ & $\begin{array}{l}>500 \\
>500\end{array}$ & $>500$ \\
\hline $\begin{array}{l}\text { 38. K.S. 우 } \\
77 \text { Jahre }\end{array}$ & 23 & 13 & 5 & $\begin{array}{l}93 \\
50 \\
29 \\
\end{array}$ & 57 & $\begin{array}{l}3,9 \\
2,5 \\
1,7 \\
\end{array}$ & 2,7 & $\begin{array}{l}330 \\
385 \\
435 \\
\end{array}$ & 383 & $\begin{array}{l}300 \\
360 \\
400 \\
\end{array}$ & 353 \\
\hline $\begin{array}{l}\text { 39. O.W. 우 } \\
65 \text { Jahre }\end{array}$ & 22 & 2 & 3 & $\begin{array}{l}60 \\
79 \\
64\end{array}$ & 68 & $\begin{array}{l}3,8 \\
4,7 \\
4,2\end{array}$ & 4,2 & $\begin{array}{l}>500 \\
>500 \\
>500\end{array}$ & $>500$ & $\begin{array}{l}>500 \\
>500 \\
>500\end{array}$ & $>500$ \\
\hline $\begin{array}{l}\text { 40. H.Bi. } 0^{\top} \\
74 \text { Jahre }\end{array}$ & 34 & 7 & 2 & $\begin{array}{r}131 \\
80 \\
89\end{array}$ & 100 & $\begin{array}{l}7,4 \\
5,7 \\
5,5\end{array}$ & 6,2 & $\begin{array}{l}385 \\
460 \\
420\end{array}$ & 422 & $\begin{array}{l}290 \\
350 \\
300\end{array}$ & 313 \\
\hline
\end{tabular}




\begin{tabular}{|c|c|c|c|c|c|c|c|c|c|c|c|}
\hline \multirow{2}{*}{$\begin{array}{l}\text { Patientendaten } \\
\text { Nr./Initialen/ } \\
\text { Geschlecht/Alter }\end{array}$} & \multirow[t]{2}{*}{ BMI } & \multirow{2}{*}{$\begin{array}{c}\text { Dialyse- } \\
\text { dauer } \\
\text { (Monate) }\end{array}$} & \multirow{2}{*}{$\begin{array}{l}\text { Diag- } \\
\text { nose- } \\
\text { klasse } \\
\text { (siehe } \\
\text { Über- } \\
\text { schrift) }\end{array}$} & \multicolumn{2}{|c|}{$\begin{array}{c}\text { Stuhlgewicht } \\
\text { (normal }<200 \mathrm{~g} / \mathrm{Tag} \text { ) }\end{array}$} & \multicolumn{2}{|c|}{$\begin{array}{c}\text { Stuhlfett } \\
\text { (normal }<7 \mathrm{~g} / \mathrm{Tag} \text { ) }\end{array}$} & \multicolumn{4}{|c|}{ Elastase 1 (normal >200 $\mu \mathrm{g} / \mathrm{g}$ Stuhl) } \\
\hline & & & & $\mathrm{g} / \mathrm{Tag}$ & $\begin{array}{l}\text { Mittelwert } \\
\text { g/Tag }\end{array}$ & g/Tag & $\begin{array}{l}\text { Mittelwert } \\
\text { g/Tag }\end{array}$ & $\begin{array}{c}\text { Methode } \\
\text { Bioserv } \\
\text { Diagnostics } \\
\mu \mathrm{g} / \mathrm{g} \text { Stuhl }\end{array}$ & $\begin{array}{c}\text { Mittel- } \\
\text { wert } \\
\mu g / g \\
\text { Stuhl }\end{array}$ & $\begin{array}{c}\text { Methode } \\
\text { ScheBo- } \\
\text { Biotech } \\
\mu \mathrm{g} / \mathrm{g} \text { Stuhl }\end{array}$ & $\begin{array}{c}\text { Mittel- } \\
\text { wert } \\
\mu \mathrm{g} / \mathrm{g} \\
\text { Stuhl }\end{array}$ \\
\hline $\begin{array}{l}\text { 41. K.R. 万 } \\
68 \text { Jahre }\end{array}$ & 26 & 25 & 1 & $\begin{array}{r}0 \\
156 \\
293 \\
\end{array}$ & 150 & $\begin{array}{c}0 \\
6,4 \\
6,0\end{array}$ & 4,1 & $\begin{array}{l}>500 \\
>500\end{array}$ & $>500$ & $\begin{array}{l}>500 \\
>500\end{array}$ & $>500$ \\
\hline $\begin{array}{l}\text { 42. I.S. 우 } \\
73 \text { Jahre }\end{array}$ & 23 & 18 & 4 & $\begin{array}{l}108 \\
141 \\
180\end{array}$ & 143 & $\begin{array}{l}6,1 \\
6,6 \\
6,4\end{array}$ & 6,4 & $\begin{array}{l}>500 \\
>500 \\
>500\end{array}$ & $>500$ & $\begin{array}{l}445 \\
460 \\
480\end{array}$ & 455 \\
\hline $\begin{array}{l}\text { 43. G.F. } \delta^{\top} \\
79 \text { Jahre }\end{array}$ & 29 & 34 & 2 & \begin{tabular}{|l|}
384 \\
109 \\
228 \\
\end{tabular} & 240 & $\begin{array}{l}7,5 \\
1,5 \\
5,2 \\
\end{array}$ & 4,7 & $\begin{array}{l}300 \\
260 \\
250 \\
\end{array}$ & 270 & $\begin{array}{l}454 \\
440 \\
495 \\
\end{array}$ & 463 \\
\hline $\begin{array}{l}\text { 44. E.M. } \sigma^{\top} \\
49 \text { Jahre }\end{array}$ & 26 & 9 & 3 & $\begin{array}{r}160 \\
95 \\
0\end{array}$ & 85 & $\begin{array}{c}7,7 \\
3,3 \\
0\end{array}$ & 3,7 & $\begin{array}{l}487 \\
445\end{array}$ & 466 & $\begin{array}{l}375 \\
320\end{array}$ & 348 \\
\hline $\begin{array}{l}\text { 45. В.M. ठ } \\
46 \text { Jahre }\end{array}$ & 23 & 5 & 3 & $\begin{array}{r}108 \\
91 \\
72 \\
\end{array}$ & 90 & $\begin{array}{l}3,3 \\
4,3 \\
2,4 \\
\end{array}$ & 3,3 & $\begin{array}{l}360 \\
325 \\
260 \\
\end{array}$ & 315 & $\begin{array}{l}>500 \\
>500 \\
>500 \\
\end{array}$ & $>500$ \\
\hline $\begin{array}{l}\text { 46. U.G. } \stackrel{+}{+} \\
62 \text { Jahre }\end{array}$ & 27 & 2 & 1 & $\begin{array}{r}0 \\
35 \\
0\end{array}$ & 12 & $\begin{array}{c}0 \\
1,7 \\
0\end{array}$ & 0,6 & $>500$ & $>500$ & 430 & 430 \\
\hline $\begin{array}{l}\text { 47. W.M. O } \\
83 \text { Jahre }\end{array}$ & 30 & 13 & 2 & $\begin{array}{r}124 \\
230 \\
147 \\
\end{array}$ & 167 & $\begin{array}{l}3,6 \\
3,8 \\
2,4 \\
\end{array}$ & 3,3 & $\begin{array}{c}>500 \\
>500 \\
480 \\
\end{array}$ & 493 & $\begin{array}{l}>500 \\
>500 \\
>500 \\
\end{array}$ & $>500$ \\
\hline $\begin{array}{l}\text { 48. W.U. }{ }^{\top} \\
70 \text { Jahre }\end{array}$ & 24 & 46 & 5 & $\begin{array}{r}22 \\
201 \\
0\end{array}$ & 74 & $\begin{array}{c}1,8 \\
8,6 \\
0\end{array}$ & 3,5 & $\begin{array}{l}>500 \\
>500\end{array}$ & $>500$ & $\begin{array}{l}>500 \\
>500\end{array}$ & $>500$ \\
\hline
\end{tabular}




\begin{tabular}{|c|c|c|c|c|c|c|c|c|c|c|c|}
\hline \multirow{2}{*}{$\begin{array}{l}\text { Patientendaten } \\
\\
\text { Nr./Initialen/ } \\
\text { Geschlecht/Alter }\end{array}$} & \multirow[t]{2}{*}{ BMI } & \multirow{2}{*}{$\begin{array}{l}\begin{array}{c}\text { Dialyse- } \\
\text { dauer }\end{array} \\
\text { (Monate) }\end{array}$} & \multirow{2}{*}{$\begin{array}{l}\text { Diag- } \\
\text { nose- } \\
\text { klasse } \\
\text { (siehe } \\
\text { Über- } \\
\text { schrift) }\end{array}$} & \multicolumn{2}{|c|}{$\begin{array}{c}\text { Stuhlgewicht } \\
\text { (normal <200 g/Tag) }\end{array}$} & \multicolumn{2}{|c|}{$\begin{array}{c}\text { Stuhlfett } \\
\text { (normal }<7 \mathrm{~g} / T a g \text { ) }\end{array}$} & \multicolumn{4}{|c|}{ Elastase 1 (normal $>200 \mu \mathrm{g} / \mathrm{g}$ Stuhl) } \\
\hline & & & & $\mathrm{g} / \mathrm{Tag}$ & $\begin{array}{l}\text { Mittelwert } \\
\text { g/Tag }\end{array}$ & $\mathrm{g} / \mathrm{Tag}$ & $\begin{array}{l}\text { Mittelwert } \\
\text { g/Tag }\end{array}$ & $\begin{array}{l}\text { Methode } \\
\text { Bioserv } \\
\text { Diagnostics } \\
\mu \mathrm{g} / \mathrm{g} \text { Stuhl }\end{array}$ & $\begin{array}{c}\text { Mittel- } \\
\text { wert } \\
\mu \mathrm{g} / \mathrm{g} \\
\text { Stuhl }\end{array}$ & $\begin{array}{c}\text { Methode } \\
\text { ScheBo- } \\
\text { Biotech } \\
\mu \mathrm{g} / \mathrm{g} \text { Stuhl }\end{array}$ & $\begin{array}{c}\text { Mittel- } \\
\text { wert } \\
\mu \mathrm{g} / \mathrm{g} \\
\text { Stuhl }\end{array}$ \\
\hline $\begin{array}{l}\text { 49. O.G. O } \\
26 \text { Jahre }\end{array}$ & 26 & 73 & 4 & $\begin{array}{r}0 \\
196 \\
0\end{array}$ & 65 & $\begin{array}{c}0 \\
\frac{13,9}{0}\end{array}$ & 4,6 & $>500$ & $>500$ & $>500$ & $>500$ \\
\hline $\begin{array}{l}\text { 50. K.Sch. }{ }^{7} \\
75 \text { Jahre }\end{array}$ & 29 & 31 & 4 & $\begin{array}{l}123 \\
\frac{220}{241}\end{array}$ & 195 & $\begin{array}{l}4,3 \\
5,5 \\
4,0\end{array}$ & 4,6 & $\begin{array}{l}>500 \\
500 \\
480\end{array}$ & 493 & $\begin{array}{l}395 \\
430 \\
395\end{array}$ & 407 \\
\hline
\end{tabular}

*) Zu geringe Stuhlmenge für eine Stuhlfettanalyse 


\subsection{Messergebnisse der Patienten}

Sämtliche Angaben für alle Patienten zu Geschlecht, Alter, BMI, Dialysedauer, Diagnoseklassen sowie sämtliche Messwerte der Stuhlgewichts-, Stuhlfett- und Elastase-1-Bestimmungen finden sich in Tabelle 2. Die Gegenüberstellung der Ergebnisse beider Enzymmessmethoden findet sich in Tabelle 3, die Einzelwerte der Patienten mit einem pathologischen Mittelwert für die Stuhlenzymmessungen finden sich in Tabelle 4.

\subsection{Elastase-1-Messungen im Stuhl}

\subsubsection{Bioserv-Diagnostics-Methode}

Der Mittelwert der Elastase-1-Messung im Stuhl nach der BioservDiagnostics-Methode fiel bei $48(96 \%)$ der Patienten normal aus und lag in zwei (4\%) Fällen (Patienten 25 u. 28) im pathologischen Bereich (Tabellen 2-4). Nur bei einer Bestimmung (Patient 25) lag der Elastase1-Wert unterhalb des Grenzwertes von $100 \mu \mathrm{g} / \mathrm{g}$ Stuhl, also in einem Bereich, in dem eine Pankreasenzymsubstitution erforderlich gewesen wäre. An den beiden anderen Tagen lagen die Messwerte jedoch nur im leicht bis mäßig reduzierten beziehungsweise im Normbereich (Tabelle 2 ).

In zwei (4\%) weiteren Fällen (Patienten 27 u. 30) fiel einer der drei Messwerte pathologisch aus, der Mittelwert lag jedoch im Normbereich. Diese Patienten wurden nicht zu denen mit einer exokrinen Pankreasinsuffizienz gezählt (Tabelle 2).

\subsubsection{ScheBo-Biotech-Methode}

Mit der ScheBo-Biotech-Methode gemessen, lagen 46 (92\%) Patienten mit ihren Messwerten im Normbereich, in vier (8\%) Fällen (Patienten. 1, 25, 27 u. 35) fiel der Mittelwert pathologisch aus (Tabellen 2-4).

Die beiden Elastase-1-Methoden stimmten nur bei einem (2\%) Patienten (Patient 25) überein und differierten in weiteren 4 (8\%) Fällen in ihren Messergebnissen (Tabellen 2-4). Bei einem weiteren Patienten (Patient 5) war zwar ein Einzelwert pathologisch, jedoch lag der Mittelwert im Normbereich. Dieser Patient wurde vereinbarungsgemäß nicht als "pankreasinsuffizient" gezählt. 
Tabelle 3. Kumulative Gegenüberstellung der Elastase-1-Messung im Stuhl mit den beiden Messmethoden

\begin{tabular}{|c|c|c|c|c|c|c|}
\hline & & & Sche & o-Biotech-I & thode & \\
\hline & & & Exokrir & Pankreasi & uffizienz & \\
\hline & & & Keine & $\begin{array}{c}\text { Leicht bis } \\
\text { mäßig } \\
\text { schwer }\end{array}$ & Schwer & Insgesamt \\
\hline & & Keine & 45 & 3 & - & 48 \\
\hline $\begin{array}{l}\text { Bloserv- } \\
\text { Diagnostics- } \\
\text { Methode }\end{array}$ & $\begin{array}{l}\text { Exokrıne } \\
\text { Pankreas- } \\
\text { insuffizienz }\end{array}$ & $\begin{array}{l}\text { Leicht bis mäßig } \\
\text { schwer }\end{array}$ & 1 & 1 & - & 2 \\
\hline & & Schwer & - & - & - & - \\
\hline & & Insgesamt & 46 & 4 & - & 50 \\
\hline
\end{tabular}


Tabelle 4.

Detaillierte Darstellung der Messwerte bei den 5 Patienten, bei denen mit einem oder beiden Elastase-1Messungen eine exokrine Pankreasinsuffizienz diagnostiziert wurde. Die Angaben in der Tabelle entsprechen jeweils Mittelwerten von 3 Bestimmungen (pathologische Werte eingekästelt)

\begin{tabular}{|c|c|c|c|c|}
\hline \multirow[b]{2}{*}{ Patienten } & \multicolumn{2}{|c|}{ Elastase 1 (normal >200 $\mu \mathrm{g} / \mathrm{g}$ Stuhl) } & \multirow[b]{2}{*}{$\begin{array}{c}\text { Stuhlgewicht } \\
\text { (normal }<200 \mathrm{~g} / \mathrm{d} \text { ) } \\
\mathrm{g} / \mathrm{d}\end{array}$} & \multirow[b]{2}{*}{$\begin{array}{c}\text { Stuhlfett } \\
\text { (normal }<7 \mathrm{~g} / \mathrm{d} \text { ) } \\
\mathrm{g} / \mathrm{d}\end{array}$} \\
\hline & $\begin{array}{c}\text { Bioserv- } \\
\text { Diagnostics- } \\
\text { Methode } \\
\mu \mathrm{g} / \mathrm{g} \text { Stuhl }\end{array}$ & $\begin{array}{c}\text { ScheBo-Biotech- } \\
\text { Methode } \\
\mu \mathrm{g} / \mathrm{g} \text { Stuhl }\end{array}$ & & \\
\hline 25 & 132 & 180 & 131 & 2.3 \\
\hline 28 & 177 & 236 & 214 & 4.9 \\
\hline 1 & 284 & 160 & 255 & 8.9 \\
\hline 27 & 232 & 134 & 280 & 10.3 \\
\hline 35 & 290 & 137 & 106 & 3.7 \\
\hline
\end{tabular}


3.4. Exokrine Pankreasinsuffizienz versus Geschlecht und Alter, Body Mass Index (BMI), Dialysedauer sowie Ursache der terminalen Niereninsuffizienz der Patienten

Die Ergebnisse der beiden Stuhlmessmethoden korrelierten weder allein noch in Kombination signifikant mit Geschlecht und Alter der Patienten, auch nicht mit dem BMI, der Hämodialysedauer und der Ursache der terminalen Niereninsuffizienz (Tabelle 5).

\subsection{Stuhlgewichts- und Stuhlfettbestimmung}

In neun (18\%) Fällen (Patienten 1, 8, 18, 26-30, 43; Tabellen 2, 6 und 7) bestand eine Diarrhoe. Diese Diarrhoe trat isoliert, das heißt ohne gleichzeitige Steatorrhoe in vier (8\%) Fällen (Patienten 18, 28, 30, 43) beziehungsweise kombiniert mit einer Steatorrhoe in fünf (10\%) Fällen (Patienten 1, 8, 26, 27, 29) auf. Bei allen Patienten lagen die Messwerte jedoch in einem Bereich zwischen $200 \mathrm{~g}$ und $300 \mathrm{~g} / \mathrm{Tag}$, also in einem Bereich, in dem man klinisch noch von einer "leichten Diarrhoe" spricht (Tabellen 2, 6 und 7).

Eine Steatorrhoe war in zehn (20\%) Fällen nachweisbar (Patienten 1, 8, 9, $12,15,16,20,26,27,29)$. Sie trat - wie oben bereits erwähnt - isoliert auf in fünf (10\%) (Patienten $9,12,15,16,20)$ und war kombiniert mit einer Diarrhoe in weiteren fünf (10\%) Fällen (Patienten 1, 8, 26, 27, 29). Die Messwerte lagen bei allen Patienten zwischen $7-15 \mathrm{~g} /$ Tag (Tabellen 2, 6. u. 7).

Nur bei zwei (4\%) Patienten mit einer Steatorrhoe (Patienten 1 u. 27) lagen auch die Elastase-1-Messungen im pathologischen Bereich (Tabellen 2 u. 4). Die Elastase-1-Werte lagen jedoch nicht unter $100 \mu \mathrm{g} / \mathrm{g} \mathrm{Stuhl,}$ also nicht in einem Bereich, in dem eine Steatorrhoe als pathologisch hätte angenommen werden müssen. 
Tabelle 5. Elastase-1-Messungen mit beiden Methoden versus Alter und Geschlecht, Body Mass Index (BMI), Ursache der terminalen Niereninsuffizienz und Dauer der Dialyse

\begin{tabular}{|c|c|c|c|c|c|c|c|c|c|}
\hline \multirow{3}{*}{ Parameter } & \multicolumn{3}{|c|}{$\begin{array}{c}\text { Elastase-1 } \\
\text { (Methode: Bioserv Diagnostics) }\end{array}$} & \multicolumn{3}{|c|}{$\begin{array}{c}\text { Elastase-1 } \\
\text { (Methode ScheBo-Biotech) }\end{array}$} & \multicolumn{3}{|c|}{$\begin{array}{c}\text { Elastase } 1 \\
\text { (Methode Bioserv Diagnostics } \\
\text { oder ScheBo-Biotech) }\end{array}$} \\
\hline & \multicolumn{2}{|c|}{ Mittelwert } & \multirow[b]{2}{*}{ p-Wert } & \multicolumn{2}{|c|}{ Mittelwert } & \multirow[b]{2}{*}{$\mathrm{p}$-Wert } & \multicolumn{2}{|c|}{ Mittelwert } & \multirow[b]{2}{*}{$\mathrm{p}$-Wert } \\
\hline & $\begin{array}{l}\text { Normal } \\
>200 \\
\mu g / g \\
\text { Stuhl }\end{array}$ & $\begin{array}{l}\text { Patholo- } \\
\text { gisch } \\
\leq 200 \mu \mathrm{g} / \mathrm{g} \\
\text { Stuhl }\end{array}$ & & $\begin{array}{c}\text { Normal } \\
>200 \mu \mathrm{g} / \mathrm{g} \\
\text { Stuhl }\end{array}$ & $\begin{array}{l}\text { Patholo- } \\
\text { gisch } \\
\leq 200 \mu \mathrm{g} / \mathrm{g} \\
\text { Stuhl }\end{array}$ & & \begin{tabular}{|c|} 
Normal \\
$200 \mu \mathrm{g} / \mathrm{g}$ \\
Stuhl
\end{tabular} & $\begin{array}{l}\text { Patholo- } \\
\text { gisch } \\
\leq 200 \mu \mathrm{g} / \mathrm{g} \\
\text { Stuhl }\end{array}$ & \\
\hline $\begin{array}{r}<50 \\
50-59 \\
60-69 \\
\geq 70 \\
\end{array}$ & $\begin{array}{l}13 \\
10 \\
13 \\
12\end{array}$ & $\begin{array}{l}0 \\
2 \\
0 \\
0\end{array}$ & $0,98^{*}$ & $\begin{array}{l}13 \\
11 \\
11 \\
11 \\
\end{array}$ & $\begin{array}{l}0 \\
1 \\
2 \\
1\end{array}$ & $0,26 *$ & $\begin{array}{l}13 \\
10 \\
11 \\
11 \\
\end{array}$ & $\begin{array}{l}0 \\
2 \\
2 \\
1\end{array}$ & $0,30 *$ \\
\hline $\begin{array}{l}\text { Männlich } \\
\text { Weiblich }\end{array}$ & $\begin{array}{l}29 \\
19 \\
\end{array}$ & $\begin{array}{l}1 \\
1\end{array}$ & $1,00 *$ & $\begin{array}{l}26 \\
20\end{array}$ & $\begin{array}{l}4 \\
0\end{array}$ & $0,14^{*}$ & $\begin{array}{l}26 \\
19 \\
\end{array}$ & $\begin{array}{l}4 \\
1\end{array}$ & $0,64^{*}$ \\
\hline BMI $\left(\mathrm{kg} / \mathrm{m}^{2}\right)$ & $\begin{array}{l}18 \\
19 \\
11\end{array}$ & $\begin{array}{l}1 \\
0 \\
1\end{array}$ & $0,85^{*}$ & $\begin{array}{l}18 \\
17 \\
11 \\
\end{array}$ & $\begin{array}{l}1 \\
2 \\
1\end{array}$ & $0,69 *$ & $\begin{array}{l}18 \\
17 \\
10\end{array}$ & $\begin{array}{l}1 \\
2 \\
2\end{array}$ & $0,31^{*}$ \\
\hline $\begin{array}{l}\text { Ursache der terminalen Nieren } \\
\text { insuffizienz } \\
\text { Hypertensive Nephropathie } \\
\text { Diabetische Nephropathie } \\
\text { Hereditäre Nephropathie } \\
\text { Autoimmune Nephropathie } \\
\text { Sonstige Nephropathien }\end{array}$ & $\begin{array}{c}14 \\
10 \\
8 \\
11 \\
5\end{array}$ & $\begin{array}{l}0 \\
0 \\
0 \\
2 \\
0\end{array}$ & $0,32 * *$ & $\begin{array}{c}13 \\
9 \\
8 \\
11 \\
5\end{array}$ & $\begin{array}{l}1 \\
1 \\
0 \\
2 \\
0\end{array}$ & $0,89 * *$ & $\begin{array}{c}13 \\
9 \\
8 \\
10 \\
5\end{array}$ & $\begin{array}{l}1 \\
1 \\
0 \\
3 \\
0\end{array}$ & $0,58 * *$ \\
\hline 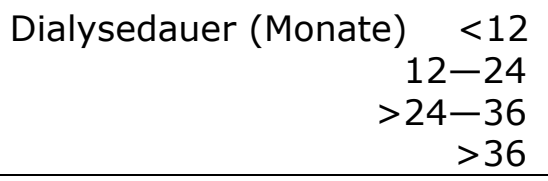 & $\begin{array}{c}15 \\
12 \\
5 \\
16\end{array}$ & $\begin{array}{l}1 \\
0 \\
0 \\
1\end{array}$ & $0,95^{*}$ & $\begin{array}{c}14 \\
11 \\
5 \\
16\end{array}$ & $\begin{array}{l}2 \\
1 \\
0 \\
1\end{array}$ & $0,45^{*}$ & $\begin{array}{c}14 \\
11 \\
5 \\
15\end{array}$ & $\begin{array}{l}2 \\
1 \\
0 \\
2\end{array}$ & $0,92 *$ \\
\hline
\end{tabular}

*Mantel-Haenszel-Test für eine Trendanalyse

**Fishers exakter Test 
Tabelle 6. Auswertung der Stuhlgewichts- und Stuhlfettbestimmung im Vergleich zur Applikation von Phosphatbindern (Renagel $₫$ [Sevelamer] bzw. Fosrenol $₫$ [Lanthancarbonat]; pathologische Werte eingekästelt)

\begin{tabular}{|c|c|c|c|c|c|c|}
\hline \multirow{2}{*}{$\begin{array}{l}\text { Patientendaten } \\
\text { Nr./Initialen/ } \\
\text { Geschlecht/Alter }\end{array}$} & \multicolumn{2}{|c|}{$\begin{array}{c}\text { Stuhlgewicht } \\
\text { (normal <200 g/Tag) }\end{array}$} & \multicolumn{2}{|c|}{$\begin{array}{c}\text { Stuhlfett } \\
\text { (normal }<7 \mathrm{~g} / \mathrm{Tag})\end{array}$} & \multicolumn{2}{|c|}{ Phosphatbinder } \\
\hline & g/Tag & $\begin{array}{l}\text { Mittelwert } \\
\text { g/Tag }\end{array}$ & $\mathrm{g} / \mathrm{Tag}$ & $\begin{array}{l}\text { Mittelwert } \\
\text { g/Tag }\end{array}$ & $\begin{array}{l}\text { Renagel }{ }^{\circledR} \\
\text { (Sevelamer) }\end{array}$ & $\begin{array}{c}\text { Fosrenol }{ }^{\circledR} \\
\text { (Lanthan- } \\
\text { carbonat) }\end{array}$ \\
\hline $\begin{array}{l}\text { 1. F.K. } 0^{x} \\
61 \text { Jahre }\end{array}$ & \begin{tabular}{|l|}
252 \\
274 \\
232 \\
\end{tabular} & 255 & \begin{tabular}{|l|}
8,3 \\
9,6 \\
8,7 \\
\end{tabular} & 8,9 & $\mathrm{Ja}$ & Nein \\
\hline $\begin{array}{l}\text { 2. E.G. 우 } \\
60 \text { Jahre }\end{array}$ & $\begin{array}{l}49 \\
60 \\
80\end{array}$ & 63 & $\begin{array}{l}2,5 \\
2,6 \\
2,3\end{array}$ & 2,5 & $\mathrm{Ja}$ & Nein \\
\hline $\begin{array}{l}\text { 3. T.S. } 0^{x} \\
20 \text { Jahre }\end{array}$ & $\begin{array}{r}51 \\
0 \\
30\end{array}$ & 27 & $\begin{array}{c}1,3 \\
0 \\
*)\end{array}$ & 0,4 & Nein & $\mathrm{Ja}$ \\
\hline $\begin{array}{l}\text { 4. N.A. 우 } \\
38 \text { Jahre }\end{array}$ & $\begin{array}{r}31 \\
0 \\
0 \\
\end{array}$ & 10 & $\begin{array}{c}1,1 \\
0 \\
0\end{array}$ & 0,4 & Nein & $\mathrm{Ja}$ \\
\hline $\begin{array}{l}\text { 5. H.S. ठ } \\
53 \text { Jahre }\end{array}$ & $\begin{array}{r}150 \\
56 \\
95 \\
\end{array}$ & 100 & \begin{tabular}{|c|}
10,0 \\
4,9 \\
5,0 \\
\end{tabular} & 6,6 & Nein & Nein \\
\hline $\begin{array}{l}\text { 6. I.M. 우 } \\
45 \text { Jahre }\end{array}$ & $\begin{array}{l}110 \\
245 \\
200 \\
\end{array}$ & 185 & $\begin{array}{l}5,7 \\
9,2 \\
4,1 \\
\end{array}$ & 6,3 & $\mathrm{Ja}$ & Nein \\
\hline $\begin{array}{l}\text { 7. H.P. ㅇ } \\
50 \text { Jahre }\end{array}$ & $\begin{array}{r}90 \\
181 \\
186\end{array}$ & 152 & $\begin{array}{l}3,1 \\
7,6 \\
5,7\end{array}$ & 5,4 & $\mathrm{Ja}$ & Nein \\
\hline $\begin{array}{l}\text { 8. C.N. }{ }^{\top} \\
54 \text { Jahre }\end{array}$ & \begin{tabular}{|l|}
160 \\
320 \\
300 \\
\end{tabular} & 260 & $\begin{array}{l}6,0 \\
9,2 \\
6,8 \\
\end{array}$ & 7,3 & Nein & $\mathrm{Ja}$ \\
\hline $\begin{array}{l}\text { 9. M.S. 万 } \\
54 \text { Jahre }\end{array}$ & $\begin{array}{r}288 \\
161 \\
0 \\
\end{array}$ & 150 & $\begin{array}{c}14,3 \\
8,0 \\
0\end{array}$ & 7,4 & Nein & Nein \\
\hline $\begin{array}{l}\text { 10. E.S. } 0^{\pi} \\
60 \text { Jahre }\end{array}$ & $\begin{array}{r}141 \\
54 \\
84 \\
\end{array}$ & 93 & $\begin{array}{l}9,0 \\
3,6 \\
3,7 \\
\end{array}$ & 5,4 & Nein & $\mathrm{Ja}$ \\
\hline $\begin{array}{l}\text { 11. H.W. ㅇ } \\
62 \text { Jahre }\end{array}$ & $\begin{array}{r}172 \\
68 \\
118 \\
\end{array}$ & 120 & $\begin{array}{l}3,4 \\
1,5 \\
3,9 \\
\end{array}$ & 2,9 & Nein & Nein \\
\hline $\begin{array}{l}\text { 12. U.W. ㅇ } \\
34 \text { Jahre }\end{array}$ & $\begin{array}{l}127 \\
262 \\
145\end{array}$ & 180 & $\begin{array}{c}5,6 \\
12,2 \\
5,5\end{array}$ & 7,8 & Nein & $\mathrm{Ja}$ \\
\hline $\begin{array}{l}\text { 13. U.S. O } \\
64 \text { Jahre }\end{array}$ & $\begin{array}{r}110 \\
96 \\
290 \\
\end{array}$ & 165 & $\begin{array}{l}2,3 \\
2,4 \\
3,4\end{array}$ & 2,7 & Nein & Nein \\
\hline
\end{tabular}




\begin{tabular}{|c|c|c|c|c|c|c|}
\hline \multirow{2}{*}{$\begin{array}{l}\text { Patientendaten } \\
\text { Nr./Initialen/ } \\
\text { Geschlecht/Alter }\end{array}$} & \multicolumn{2}{|c|}{$\begin{array}{c}\text { Stuhlgewicht } \\
\text { (normal <200 g/Tag) }\end{array}$} & \multicolumn{2}{|c|}{$\begin{array}{c}\text { Stuhlfett } \\
\text { (normal }<7 \mathrm{~g} / \mathrm{Tag} \text { ) }\end{array}$} & \multicolumn{2}{|c|}{ Phosphatbinder } \\
\hline & g/Tag & $\begin{array}{l}\text { Mittelwert } \\
\text { g/Tag }\end{array}$ & g/Tag & $\begin{array}{l}\text { Mittelwert } \\
\text { g/Tag }\end{array}$ & $\begin{array}{l}\text { Renagel } \circledast \\
\text { (Sevelamer) }\end{array}$ & $\begin{array}{c}\text { Fosrenol }{ }^{\circledR} \\
\text { (Lanthan- } \\
\text { carbonat) } \\
\end{array}$ \\
\hline $\begin{array}{l}\text { 14. K.E. } \sigma^{\pi} \\
38 \text { Jahre }\end{array}$ & $\begin{array}{r}126 \\
89 \\
73 \\
\end{array}$ & 96 & $\begin{array}{l}3,4 \\
2,2 \\
2,1\end{array}$ & 2,6 & Nein & Nein \\
\hline $\begin{array}{l}\text { 15. U.R. P } \\
55 \text { Jahre }\end{array}$ & $\begin{array}{r}88 \\
196 \\
52 \\
\end{array}$ & 112 & \begin{tabular}{|c|}
8,3 \\
11,7 \\
4,1 \\
\end{tabular} & 8,0 & $\mathrm{Ja}$ & Nein \\
\hline $\begin{array}{l}\text { 16. M.B. } 0^{\pi} \\
48 \text { Jahre }\end{array}$ & $\begin{array}{r}98 \\
216 \\
171 \\
\end{array}$ & 162 & $\begin{array}{c}5,2 \\
10,7 \\
9,0 \\
\end{array}$ & 8,3 & Nein & $\mathrm{Ja}$ \\
\hline $\begin{array}{l}\text { 17. M.K. ठ } \\
32 \text { Jahre }\end{array}$ & $\begin{array}{r}120 \\
52 \\
0\end{array}$ & 57 & $\begin{array}{c}11,6 \\
2,0 \\
0\end{array}$ & 4,5 & Nein & Nein \\
\hline $\begin{array}{l}\text { 18. H.D. } 0^{\pi} \\
56 \text { Jahre }\end{array}$ & $\begin{array}{l}380 \\
180 \\
165 \\
\end{array}$ & 240 & $\begin{array}{l}5,1 \\
3,5 \\
3,0\end{array}$ & 3,9 & $\mathrm{Ja}$ & Nein \\
\hline $\begin{array}{l}\text { 19. W.D. } 0^{\top} \\
66 \text { Jahre }\end{array}$ & $\begin{array}{r}56 \\
102 \\
0 \\
\end{array}$ & 53 & \begin{tabular}{c|}
7,5 \\
7,7 \\
0 \\
\end{tabular} & 5,1 & $\mathrm{Ja}$ & Nein \\
\hline $\begin{array}{l}\text { 20. B.K. } \sigma^{\top} \\
54 \text { Jahre }\end{array}$ & $\begin{array}{r}163 \\
92 \\
128 \\
\end{array}$ & 128 & $\begin{array}{c}10,5 \\
5,3 \\
6,6 \\
\end{array}$ & 7,5 & Nein & $\mathrm{Ja}$ \\
\hline $\begin{array}{l}\text { 21. W.F. } 0^{\top} \\
60 \text { Jahre }\end{array}$ & $\begin{array}{r}44 \\
177 \\
102 \\
\end{array}$ & 108 & $\begin{array}{l}2,4 \\
6,5 \\
4,9 \\
\end{array}$ & 4,6 & Nein & $\mathrm{Ja}$ \\
\hline $\begin{array}{l}\text { 22. B.S. ㅇ } \\
51 \text { Jahre }\end{array}$ & $\begin{array}{l}170 \\
160 \\
217 \\
\end{array}$ & 182 & $\begin{array}{l}3,9 \\
3,4 \\
4,1 \\
\end{array}$ & 3,8 & Nein & $\mathrm{Ja}$ \\
\hline $\begin{array}{l}\text { 23. H.Dr. o } \\
56 \text { Jahre }\end{array}$ & $\begin{array}{r}54 \\
0 \\
106\end{array}$ & 55 & $\begin{array}{c}1,3 \\
0 \\
2,6\end{array}$ & 1,2 & Nein & Nein \\
\hline $\begin{array}{l}\text { 24. M.M. } \stackrel{+}{ } \\
48 \text { Jahre }\end{array}$ & $\begin{array}{r}0 \\
0 \\
105\end{array}$ & 35 & $\begin{array}{c}0 \\
0 \\
7,2\end{array}$ & 2,4 & $\mathrm{Ja}$ & Nein \\
\hline $\begin{array}{l}\text { 25. K.G. } 0^{\top} \\
52 \text { Jahre }\end{array}$ & $\begin{array}{r}182 \\
56 \\
155\end{array}$ & 131 & $\begin{array}{l}2,1 \\
0,6 \\
4,3\end{array}$ & 2,3 & Nein & $\mathrm{Ja}$ \\
\hline $\begin{array}{l}\text { 26. E.Go. } 0^{\pi} \\
64 \text { Jahre }\end{array}$ & $\begin{array}{l}166 \\
271 \\
174 \\
\end{array}$ & 205 & \begin{tabular}{|l|}
14,0 \\
16,3 \\
12,3 \\
\end{tabular} & 14,2 & $\mathrm{Ja}$ & Nein \\
\hline $\begin{array}{l}\text { 27. B.Kö. } 0^{\pi} \\
63 \text { Jahre }\end{array}$ & \begin{tabular}{|l|}
298 \\
159 \\
383 \\
\end{tabular} & 280 & \begin{tabular}{|c|}
13,5 \\
5,0 \\
12,5 \\
\end{tabular} & 10,3 & $\mathrm{Ja}$ & Nein \\
\hline $\begin{array}{l}\text { 28. E.B. 우 } \\
58 \text { Jahre }\end{array}$ & \begin{tabular}{l|}
171 \\
234 \\
236 \\
\end{tabular} & 214 & $\begin{array}{l}4,5 \\
6,7 \\
3,6\end{array}$ & 4,9 & Nein & $\mathrm{Ja}$ \\
\hline
\end{tabular}




\begin{tabular}{|c|c|c|c|c|c|c|}
\hline \multirow{2}{*}{$\begin{array}{l}\text { Patientendaten } \\
\text { Nr./Initialen/ } \\
\text { Geschlecht/Alter }\end{array}$} & \multicolumn{2}{|c|}{$\begin{array}{c}\text { Stuhlgewicht } \\
\text { (normal <200 g/Tag) }\end{array}$} & \multicolumn{2}{|c|}{$\begin{array}{c}\text { Stuhlfett } \\
\text { (normal }<7 \mathrm{~g} / \mathrm{Tag})\end{array}$} & \multicolumn{2}{|c|}{ Phosphatbinder } \\
\hline & g/Tag & $\begin{array}{l}\text { Mittelwert } \\
\text { g/Tag }\end{array}$ & g/Tag & $\begin{array}{l}\text { Mittelwert } \\
\text { g/Tag }\end{array}$ & $\begin{array}{l}\text { Renagel } \mathbb{} \\
\text { (Sevelamer) }\end{array}$ & $\begin{array}{c}\text { Fosrenol }{ }^{\circledR} \\
\text { (Lanthan- } \\
\text { carbonat) } \\
\end{array}$ \\
\hline $\begin{array}{l}\text { 29. V.T. } 0^{\top} \\
53 \text { Jahre }\end{array}$ & \begin{tabular}{|l|}
238 \\
175 \\
202 \\
\end{tabular} & 205 & \begin{tabular}{c|}
9,6 \\
10,4 \\
7,4
\end{tabular} & 9,1 & Nein & Nein \\
\hline $\begin{array}{l}\text { 30. A.F. ㅇ } \\
42 \text { Jahre }\end{array}$ & \begin{tabular}{|l|}
386 \\
155 \\
286
\end{tabular} & 275 & $\begin{array}{l}5,5 \\
4,2 \\
4,2\end{array}$ & 4,6 & Nein & Nein \\
\hline $\begin{array}{l}\text { 31. S.H. }{ }^{\nearrow} \\
23 \text { Jahre }\end{array}$ & $\begin{array}{r}144 \\
110 \\
0\end{array}$ & 85 & $\begin{array}{c}4,9 \\
3,0 \\
0\end{array}$ & 2,6 & $\mathrm{Ja}$ & Nein \\
\hline $\begin{array}{l}\text { 32. D.S. ㅇ } \\
65 \text { Jahre }\end{array}$ & $\begin{array}{r}86 \\
141 \\
0 \\
\end{array}$ & 76 & $\begin{array}{c}4,3 \\
7,0 \\
0 \\
\end{array}$ & 3,8 & Nein & Nein \\
\hline $\begin{array}{l}\text { 33. E.Bi. 우 } \\
80 \text { Jahre }\end{array}$ & $\begin{array}{r}0 \\
178 \\
0 \\
\end{array}$ & 59 & $\begin{array}{c}0 \\
\frac{12,7}{0}\end{array}$ & 4,2 & Nein & Nein \\
\hline $\begin{array}{l}\text { 34. A.K. } 0^{7} \\
76 \text { Jahre }\end{array}$ & $\begin{array}{r}64 \\
144 \\
85 \\
\end{array}$ & 98 & $\begin{array}{l}4,3 \\
7,4 \\
6,7\end{array}$ & 6,1 & Nein & Nein \\
\hline $\begin{array}{l}\text { 35. W.T. } 0^{\pi} \\
72 \text { Jahre }\end{array}$ & $\begin{array}{r}176 \\
133 \\
10\end{array}$ & 106 & $\begin{array}{l}6,4 \\
4,6 \\
*)\end{array}$ & 3,7 & Nein & Nein \\
\hline $\begin{array}{l}\text { 36. H.B. 우 } \\
71 \text { Jahre }\end{array}$ & $\begin{array}{r}30 \\
187 \\
198 \\
\end{array}$ & 138 & $\begin{array}{l}1,1 \\
2,9 \\
1,1\end{array}$ & 1,7 & Nein & $\mathrm{Ja}$ \\
\hline $\begin{array}{l}\text { 37. C.T. ㅇ } \\
78 \text { Jahre }\end{array}$ & $\begin{array}{r}19 \\
0 \\
52\end{array}$ & 24 & $\begin{array}{c}1,2 \\
0 \\
3\end{array}$ & 1,4 & Nein & Nein \\
\hline $\begin{array}{l}\text { 38. K.S. ㅇ } \\
77 \text { Jahre }\end{array}$ & $\begin{array}{l}93 \\
50 \\
29\end{array}$ & 57 & $\begin{array}{l}3,9 \\
2,5 \\
1,7\end{array}$ & 2,7 & $\mathrm{Ja}$ & Nein \\
\hline $\begin{array}{l}\text { 39. O.W. ㅇ } \\
65 \text { Jahre }\end{array}$ & $\begin{array}{l}60 \\
79 \\
64\end{array}$ & 68 & $\begin{array}{l}3,8 \\
4,7 \\
4,2\end{array}$ & 4,2 & $\mathrm{Ja}$ & Nein \\
\hline $\begin{array}{l}\text { 40. H.Bi. } 0^{\pi} \\
74 \text { Jahre }\end{array}$ & $\begin{array}{r}131 \\
80 \\
89 \\
\end{array}$ & 100 & \begin{tabular}{|l|}
7,4 \\
5,7 \\
5,5
\end{tabular} & 6,2 & $\mathrm{Ja}$ & Nein \\
\hline $\begin{array}{l}\text { 41. K.R. } \sigma^{\pi} \\
68 \text { Jahre }\end{array}$ & $\begin{array}{r}0 \\
156 \\
293 \\
\end{array}$ & 150 & $\begin{array}{c}0 \\
6,4 \\
6,0 \\
\end{array}$ & 4,1 & Nein & Nein \\
\hline $\begin{array}{l}\text { 42. I.S. O+ } \\
73 \text { Jahre }\end{array}$ & $\begin{array}{l}108 \\
141 \\
180 \\
\end{array}$ & 143 & $\begin{array}{l}6,1 \\
6,6 \\
6,4\end{array}$ & 6,4 & $\mathrm{Ja}$ & Nein \\
\hline $\begin{array}{l}\text { 43. G.F. } 0^{7} \\
79 \text { Jahre }\end{array}$ & \begin{tabular}{|l|}
384 \\
109 \\
228 \\
\end{tabular} & 240 & $\begin{array}{l}7,5 \\
1,5 \\
5,2 \\
\end{array}$ & 4,7 & Nein & $\mathrm{Ja}$ \\
\hline $\begin{array}{l}\text { 44. E.M. } 0^{\top} \\
49 \text { Jahre }\end{array}$ & $\begin{array}{r}160 \\
95 \\
0\end{array}$ & 85 & $\begin{array}{c}7,7 \\
3,3 \\
0\end{array}$ & 3,7 & $\mathrm{Ja}$ & Nein \\
\hline
\end{tabular}




\begin{tabular}{|c|c|c|c|c|c|c|}
\hline \multirow{2}{*}{$\begin{array}{l}\text { Patientendaten } \\
\text { Nr./Initialen/ } \\
\text { Geschlecht/Alter }\end{array}$} & \multicolumn{2}{|c|}{$\begin{array}{c}\text { Stuhlgewicht } \\
\text { (normal <200 g/Tag) }\end{array}$} & \multicolumn{2}{|c|}{$\begin{array}{c}\text { Stuhlfett } \\
\text { (normal }<7 \mathrm{~g} / \mathrm{Tag})\end{array}$} & \multicolumn{2}{|c|}{ Phosphatbinder } \\
\hline & g/Tag & $\begin{array}{l}\text { Mittelwert } \\
\text { g/Tag }\end{array}$ & $\mathrm{g} / \mathrm{Tag}$ & $\begin{array}{l}\text { Mittelwert } \\
\text { g/Tag }\end{array}$ & $\begin{array}{l}\text { Renagel }{ }^{\circledR} \\
\text { (Sevelamer) }\end{array}$ & $\begin{array}{c}\text { Fosrenol }{ }^{\circledR} \\
\text { (Lanthan- } \\
\text { carbonat) }\end{array}$ \\
\hline $\begin{array}{l}\text { 45. B.M. }{ }^{\top} \\
46 \text { Jahre }\end{array}$ & $\begin{array}{r}108 \\
91 \\
72 \\
\end{array}$ & 90 & $\begin{array}{l}3,3 \\
4,3 \\
2,4\end{array}$ & 3,3 & $\mathrm{Ja}$ & Nein \\
\hline $\begin{array}{l}\text { 46. U.G. 우 } \\
62 \text { Jahre }\end{array}$ & $\begin{array}{r}0 \\
35 \\
0\end{array}$ & 12 & $\begin{array}{c}0 \\
1,7 \\
0\end{array}$ & 0,6 & Nein & $\mathrm{Ja}$ \\
\hline $\begin{array}{l}\text { 47. W.M. O } \\
83 \text { Jahre }\end{array}$ & $\begin{array}{l}124 \\
230 \\
147\end{array}$ & 167 & $\begin{array}{l}3,6 \\
3,8 \\
2,4\end{array}$ & 3,3 & Nein & Nein \\
\hline $\begin{array}{l}\text { 48. W.U. } 0^{7} \\
70 \text { Jahre }\end{array}$ & $\begin{array}{r}22 \\
201 \\
0\end{array}$ & 74 & $\begin{array}{c}1,8 \\
\frac{8,6}{0}\end{array}$ & 3,5 & Nein & Nein \\
\hline $\begin{array}{l}\text { 49. O.G. } 0^{\pi} \\
26 \text { Jahre }\end{array}$ & $\begin{array}{r}0 \\
196 \\
0\end{array}$ & 65 & $\begin{array}{c}0 \\
\frac{13,9}{0}\end{array}$ & 4,6 & Nein & $\mathrm{Ja}$ \\
\hline $\begin{array}{r}\text { 50. K.Sch. } 0^{7} \\
75 \text { Jahre }\end{array}$ & \begin{tabular}{|l|}
223 \\
2201 \\
241
\end{tabular} & 195 & $\begin{array}{l}4,3 \\
5,5 \\
4,0\end{array}$ & 4,6 & Nein & $\mathrm{Ja}$ \\
\hline
\end{tabular}

*Zu wenig Stuhl für eine Stuhlfettanalyse, Stuhlfettgehalt als 0 bewertet.

Tabelle 7. Kumulative Gegenüberstellung von Patienten mit/ohne Diarrhoe beziehungsweise mit/ohne Steatorrhoe

\begin{tabular}{|c|l|c|c|c|c|}
\cline { 2 - 6 } \multicolumn{2}{c|}{} & \multicolumn{3}{c|}{ Diarrhoe } & \multirow{2}{*}{} \\
\cline { 2 - 6 } \multicolumn{2}{c|}{} & Keine & $\begin{array}{c}\text { Leicht bis } \\
\text { mäßig } \\
\text { schwer }\end{array}$ & Schwer & Insgesamt \\
\hline \multirow{5}{*}{ Steatorrhoe } & Keine & 36 & 4 & - & 40 \\
\cline { 2 - 6 } & $\begin{array}{l}\text { Leicht bis } \\
\text { mäßig } \\
\text { schwer }\end{array}$ & 5 & 5 & - & 10 \\
\cline { 2 - 6 } & Schwer & - & - & - & - \\
\cline { 2 - 6 } & Insgesamt & 41 & 9 & - & 50 \\
\hline
\end{tabular}


3.6. Stuhlgewichts- und Stuhlfettmessergebnisse versus Elastase-1Messergebnisse im Stuhl

Die Ergebnisse der Stuhlgewichts- und Stuhlfettanalyse korrelierten nicht signifikant mit den Ergebnissen der Elastase-1-Messungen (Tabelle 8).

3.7. Stuhlgewichts- und Stuhlfettmessergebnisse versus Therapie mit Phosphatbindern

Bei sechs (67\%) der neun Patienten mit einer leichten bis mäßig schweren Diarrhoe wurde auch eine Therapie mit einem der beiden Phosphatbinder Sevelamer oder Lanthancarbonat durchgeführt (Tabelle 6). Ebenso wurde eine Phosphatbindertherapie bei fünf $(50 \%)$ der zehn Patienten mit einer Steatorrhoe vorgenommen (Tabelle 6). Die fünf weiteren Patienten mit leichter bis mäßig schwerer Steatorrhoe sowie drei Patienten mit leichter bis mäßig schwerer Diarrhoe nahmen keine entsprechenden Medikamente. Alles in allem bestand keine signifikante Korrelation zwischen Stuhlgewicht und Stuhlfett und der Gabe von Phosphatbindern (weder allein noch in Kombination) (Tabelle 9). 
Tabelle 8.

Ergebnisse der Stuhlgewichts- und Stuhlfettbestimmung versus Elastase-1-Messung

\begin{tabular}{|c|c|c|c|c|c|c|}
\hline \multirow{3}{*}{ Messparameter } & \multicolumn{6}{|c|}{ Elastase-1-Messung } \\
\hline & \multicolumn{3}{|c|}{$\begin{array}{c}\text { Bioserv-Diagnostics-Methode } \\
\text { pathologisch? }\end{array}$} & \multicolumn{3}{|c|}{$\begin{array}{c}\text { ScheBo-Biotech-Methode } \\
\text { pathologisch? }\end{array}$} \\
\hline & Nein & $\mathrm{Ja}$ & p-Wert* & Nein & $\mathrm{Ja}$ & p-Wert* \\
\hline \multicolumn{7}{|l|}{ Stuhlgewicht (Mittelwert) } \\
\hline Normal (<200 g/Tag) & 40 & 1 & & 39 & 2 & \\
\hline Pathologisch (Diarrhoe) & 8 & 1 & 0,33 & 7 & 2 & 0,14 \\
\hline \multicolumn{7}{|l|}{ Stuhlfett (Mittelwert) } \\
\hline Normal (<7 g/Tag) & 38 & 2 & & 38 & 2 & \\
\hline Pathologisch (Steatorrhoe) & 10 & 0 & 1,00 & 8 & 2 & 0,17 \\
\hline
\end{tabular}

*Fisher's exakter Test 
Tabelle 9.

Ergebnisse der Stuhlgewichts- und Stuhlfettbestimmung versus Therapie mit Phosphatbindern (Renagel ${ }^{\circ}$ [Sevelamer] und Fosrenol® [Lanthancarbonat])

\begin{tabular}{|c|c|c|c|c|c|c|c|c|c|}
\hline \multirow{3}{*}{ Messparameter } & \multicolumn{9}{|c|}{ Therapie mit Phosphatbindern } \\
\hline & \multicolumn{3}{|c|}{$\begin{array}{l}\text { Renagel }{ }^{\circledR} \\
\text { (Sevelamer) } \\
\text { pathologisch }\end{array}$} & \multicolumn{3}{|c|}{$\begin{array}{c}\text { Fosrenol }{ }^{\circledR} \\
\text { (Lanthancarbonat) } \\
\text { pathologisch }\end{array}$} & \multicolumn{3}{|c|}{$\begin{array}{c}\text { Renagel }{ }^{\circledR} \text { (Sevelamer) oder } \\
\text { Fosrenol }{ }^{\circledR} \text { (Lanthancarbonat) } \\
\text { pathologisch }\end{array}$} \\
\hline & Nein & $\mathrm{Ja}$ & p-Wert* & Nein & $\mathrm{Ja}$ & p-Wert* & Nein & $\mathrm{Ja}$ & $\mathrm{p}$-Wert* \\
\hline $\begin{array}{r}\text { Stuhlgewicht (Mittelwert) } \\
\text { Normal (<200 g/Tag) } \\
\text { Pathologisch (Diarrhoe) }\end{array}$ & $\begin{array}{r}28 \\
5\end{array}$ & $\begin{array}{c}13 \\
4\end{array}$ & 0,47 & $\begin{array}{c}28 \\
6\end{array}$ & $\begin{array}{c}13 \\
3\end{array}$ & $1,00 *$ & $\begin{array}{c}15 \\
2\end{array}$ & $\begin{array}{c}26 \\
7\end{array}$ & 0,70 \\
\hline $\begin{array}{r}\text { Stuhlfett (Mittelwert) } \\
\text { Normal (<7g/Tag) } \\
\text { Pathologisch (Steatorrhoe) }\end{array}$ & $\begin{array}{c}27 \\
6\end{array}$ & $\begin{array}{c}13 \\
4\end{array}$ & 0,72 & $\begin{array}{c}28 \\
6\end{array}$ & $\begin{array}{c}12 \\
4\end{array}$ & $0,71^{*}$ & $\begin{array}{c}15 \\
2\end{array}$ & $\begin{array}{c}25 \\
8\end{array}$ & 0,46 \\
\hline
\end{tabular}

*Fisher's exakter Test 


\section{Diskussion}

\subsection{Diagnostik der exokrinen Pankreasinsuffizienz}

Zur Untersuchung der exokrinen Pankreasfunktion stehen zwei Möglichkeiten zur Verfügung:

- Direkte, invasive Verfahren, mit denen die Produkte der Pankreassekretion wie Bikarbonat und Enzyme erfasst werden

- Indirekte, nicht invasive Verfahren, bei denen der Nachweis einer verminderten Verdauungsleistung (Maldigestion) auf eine verminderte Pankreassekretion schließen lässt.

Der Sekretin-Pankreozymin-Test (SPT) und seine Modifikationen sind das genaueste Verfahren zum Beweis oder Ausschluss einer exokrinen Pankreasinsuffizienz (Lankisch 1982; 1993). Dieser Test gilt als aufwendig, kostspielig und belastend für den Patienten und war daher auch schon früher in nur wenigen Kliniken etabliert. Der Aufwand und die Kosten sind vergleichbar mit denen der bildgebenden Verfahren wie endoskopischretrograde Cholangio-Pankreatikografie (ERCP), Magnet-Resonanz-Cholangio-Pankreatikografie (MRCP) oder Computertomografie (CT). Auch kann die Duodenalsonde heutzutage endoskopisch und damit rasch platziert werden, da zur Abklärung von Oberbauchbeschwerden ohnehin eine Ösophagogastroduodenoskopie erforderlich ist. Trotzdem muss es als realistisch angesehen werden, dass dieser Test in Deutschland und auch weltweit nur noch ganz vereinzelt - wenn überhaupt - durchgeführt wird.

In der Praxis werden derzeit zur Überprüfung der Pankreasfunktion weit weniger sensitive und spezifische indirekte Pankreasfunktionstests wie die fotometrische Chymotrypsinbestimmung im Stuhl oder die Elastase-1Messung eingesetzt. 
Zur Chymotrypsinbestimmung ist es - im Gegensatz zur Elastase-1-Messung - erforderlich, die Pankreasenzymtherapie fünf Tage vor der Untersuchung abzusetzen. Falsch-pathologische Ergebnisse sind möglich

○ bei Durchfallerkrankungen anderer Genese

- bei einheimischer Sprue (verminderte Freisetzung der Hormone, die das Pankreas stimulieren)

○ nach Billroth-II-Gastrektomie (postzibale Asynchronie)

- bei reduzierter Ernährung bei Kachexie (verminderte Pankreasenzymsynthese durch Eiweißmangel) und

- bei Verschlussikterus (fehlende Stimulation des Pankreas durch die Galle).

Die Sensitivität der fäkalen Elastase-1-Messung zur Diagnose einer chronischen Pankreatitis beziehungsweise einer exokrinen Pankreasinsuffizienz ist mehrfach untersucht worden (Tabelle 10). Wenn im Vergleich zu der Enzymbestimmung die Ergebnisse der ERCP herangezogen wurden, kamen in der Regel die Cambridge-Klassifikation (Sarner u. Cotton 1984a; b) oder zur Prüfung der exokrinen Pankreasfunktion der SPT beziehungsweise einer seiner Modifikationen zum Einsatz (Tabelle 10). Die exokrine Pankreasinsuffizienz wurde in der Regel als "leicht", "mäßig schwer", "mäßig schwer bis schwer" und "schwer" eingestuft.

Wenn chronische Pankreatitis und exokrine Pankreasinsuffizienz zusammen genommen wurden, ergaben sich folgende Ergebnisse: In den meisten Studien hatte die fäkale Elastase-1-Messung in schweren Fällen eine Sensitivität von 100\% (Domínguez-Muñoz et al. 1995; Glasbrenner et al. 1996; Löser et al. 1996; Gullo et al. 1999; Lüth et al. 2001). 
Tabelle 10.

Sensitivität der Bestimmung der fäkalen Elastase-1 zur Diagnose einer chronischen Pankreatitis/exokrinen Pankreasinsuffizienz (Lankisch 2004)

\begin{tabular}{|c|c|c|c|c|c|}
\hline \multirow[b]{2}{*}{ Autoren* } & \multirow[b]{2}{*}{$\begin{array}{c}\text { Goldstandard zum } \\
\text { Vergleich }\end{array}$} & \multicolumn{4}{|c|}{$\begin{array}{l}\text { Chronische Pankreatitis/ } \\
\text { exokrine Pankreasinsuffizienz }\end{array}$} \\
\hline & & Leicht & $\begin{array}{l}\text { Mäßig } \\
\text { schwer }\end{array}$ & $\begin{array}{l}\text { Mäßig schwer } \\
\text { bis schwer }\end{array}$ & Schwer \\
\hline Choi et al. (1998) & $\begin{array}{l}\text { Intraduktaler } \\
\text { Sekretintest }\end{array}$ & $33 \%$ & - & $78 \% *$ & - \\
\hline Domínguez-Muñoz et al. (1995) & $\mathrm{ERCP} * *$ & 0 & $100 \%$ & - & $100 \%$ \\
\hline Glasbrenner et al. (1996) & $\mathrm{ERCP} * *$ & $47 \%$ & $49 \%$ & - & $100 \%$ \\
\hline Gullo et al. (1999) & $\begin{array}{l}\text { Ultrasonografie } \\
\text { plus ERCP }\end{array}$ & $22 \%$ & $77 \%$ & - & $100 \%$ \\
\hline Lankisch et al. (1998) & $\begin{array}{c}\text { Sekretin- } \\
\text { Pankreozymin-Test }\end{array}$ & $40 \%$ & $33 \%$ & - & $82 \%$ \\
\hline Löser et al. (1996) & $\begin{array}{l}\text { Sekretin-Caerulein- } \\
\text { Test }\end{array}$ & $63 \%$ & $100 \%$ & - & $100 \%$ \\
\hline Lüth et al. (2001) & $\begin{array}{c}\text { Sekretin-Caerulein- } \\
\text { Test }\end{array}$ & $65 \%$ & $89 \%$ & - & $100 \%$ \\
\hline
\end{tabular}

*Die Autoren differenzieren die exokrine Pankreasinsuffizienz unterschiedlich: Choi et al. (1998) in „leicht" und „mäßig schwer bis schwer", die anderen Autoren in „leicht”, „mäßig schwer" und "schwer"

**Beurteilt nach der Cambridge-Klassifikation (Sarner u. Cotton 1984a; b) 
Tabelle 11

Spezifität der fäkalen Elastase-1-Messung zur Diagnose einer chronischen Pankreatitis beziehungsweise einer exokrinen Pankreasinsuffizienz

\begin{tabular}{|c|c|c|c|}
\hline Autoren & Goldstandard zum Vergleich & $\begin{array}{c}\text { Elastase-1 } \\
(<200 \mu \mathrm{g} / \mathrm{g} \text { Stuhl })\end{array}$ & $\begin{array}{l}\text { Chymotrypsin } \\
\text { (<3 U/g Stuhl) }\end{array}$ \\
\hline Amann et al. (1996) & Kombination von Tests $^{1}$ & 71 & - \\
\hline Domínguez-Muñoz et al. (1995) & ERCP* & 90 & $100^{2}$ \\
\hline Glasbrenner et al. (1996) & ERCP & 78 & 82 \\
\hline Gullo et al. (1999) & Ultrasonografie plus ERCP & 96 & $85^{4}$ \\
\hline Lankisch et al. (1998) & Sekretin-Pankreozymin-Test & 94 & $91^{4}$ \\
\hline
\end{tabular}

*Beurteilt nach der Cambridge-Klassifikation (Sarner u. Cotton 1984a; b)

${ }^{1}$ Kombination von typischem Krankheitsverlauf und einem oder mehreren der folgenden Parameter: Intraduktaler Sekretin-Test (IDST), Nachweis von Pankreasverkalkungen, pathologische ERCP, oder frühere Operationen wegen einer chronischen Pankreatitis

${ }^{2}$ Gastrointestinale Erkrankung mit Einfluss auf die Verdauung

${ }^{3}$ Gastrointestinale Erkrankung ohne Einfluss auf die Verdauung

${ }^{4}$ Chymotrypsin $<6 \mathrm{U} / \mathrm{g}$ 
In mäßig schweren Fällen lag die Sensitivität nur in zwei Studien bei 100\% (Domínguez-Muñoz et al. 1995; Löser et al. 1996), während in den anderen Studien die Sensitivität zwischen 33\% und 89\% lag (Glasbrenner et al. 1996; Choi et al. 1998; Lankisch et al. 1998; Gullo et al. 1999; Lüth et al. 2001). Bei der leichten Form ergab sich eine Sensitivität zwischen 0 und 65\% (Domínguez-Muñoz et al. 1995; Glasbrenner et al. 1996; Löser et al. 1996; Choi et al. 1998; Lankisch et al. 1998; Gullo et al. 1999; Lüth et al. 2001).

Manche Autoren verglichen die Spezifität der Elastase-1-Bestimmung mit dem Chymotrypsin und anderen, älteren indirekten Pankreasfunktionstests (Tabelle 11).

Gewöhnlich wurde eine Chymotrypsin-Konzentration von $<3 \mathrm{U} / \mathrm{g}$ Stuhl als pathologisch eingestuft, während bei einem Wert von 3-6 U/g Stuhl der Verdacht auf eine exokrine Pankreasinsuffizienz bestand. Unter Nutzung des Grenzwertes von $3 \mathrm{U} / \mathrm{g}$ Stuhl für Chymotrypsin war die Elastase-1Messung spezifischer in zwei Studien (Löser et al. 1996; Gullo et al. 1999), aber nicht in anderen Untersuchungen (Domínguez-Muñoz et al. 1995; Glasbrenner et al. 1996). Unter Zugrundelegung eines Grenzwertes von $6 \mathrm{U} / \mathrm{g}$ Stuhl lag die Spezifität beider Bestimmungen in etwa gleich in zwei Untersuchungen (Lankisch et al. 1998; Lüth et al. 2001), aber in einer dritten (Gullo et al. 1999) fielen die Werte für die Elastase-1-Messung besser aus.

In einer weiteren Untersuchung, die allerdings mit $13 \mathrm{U} / \mathrm{g}$ Stuhl für Chymotrypsin einen weitaus höheren Grenzwert annahm, war die Elastase-1 dem Chymotrypsin in der Diagnostik der exokrinen Pankreasinsuffizienz erneut überlegen (Brydon et al. 2004).

Stuhlenzymbestimmungen sind nicht voll verwertbar bei Diarrhoe, da es dabei zu einer Verdünnung der Enzymkonzentration kommt, was offenbar besonders für die Elastase-1-Messung im Stuhl gilt (Fischer et al. 2001; Brydon et al. 2004;). 
Alles in allem ergeben sich durch den ELISA-Test unabhängig von dem gewählten Verfahren im Zusammenhang mit morphologischen Methoden wie Ultraschall und Computertomografie folgende Interpretationsmöglichkeiten:

- Der ELISA-Test fällt ebenso wie die morphologischen Untersuchungsverfahren pathologisch aus: dann liegt eine chronische Pankreatitis vor.

- Mit beiden Untersuchungsmethoden werden normale Befunde erzielt: dann ist eine chronische Pankreatitis ausgeschlossen, eine leichte bis mäßige exokrine Pankreasinsuffizienz jedoch möglich.

- Die morphologischen Verfahren zeigen ein normales Pankreas, während die Elastase-1 erniedrigt ist: es liegt eine exokrine Pankreasinsuffizienz vor, deren Ätiologie zu klären ist.

Alles in allem ist also die fäkale Elastase-1-Messung ein gut brauchbarer Test zur Erkennung der schweren exokrinen Pankreasinsuffizienz, Fälle mit leichter bis mäßig schwerer Insuffizienz können jedoch mit dieser Untersuchungsmethode unentdeckt bleiben.

Die Pankreas-Elastase-1 stellt ein vom exokrinen Pankreas sezerniertes Enzym dar, das den Darm ohne einen nennenswerten Abbau passiert.

Der heutzutage am weitesten verbreitete Test für die fäkale Elastase-1Messung ist der kommerziell erhältliche monoklonale ELISA-Test der Firma ScheBo-Biotech, Wittenberg. Der später entwickelte, ebenfalls kommerziell erhältliche Test der Firma Bioserv Diagnostics, Rostock, ist ein polyklonaler ELISA-Test. Nach Untersuchungen im Städtischen Klinikum Lüneburg hat er eine höhere Spezifität als der Test der Firma ScheBoBiotech (Hahn et al. 2005). Es wird aber spekuliert, dass dieser Test ein bislang unbekanntes antigenes Epitop diagnostiziert, das sich von der Pankreas-Elastase-1 unterscheidet (Schneider et al. 2005). Zu dieser Diskussion trägt bei, dass bis heute nicht ganz geklärt ist, welche Identität die Hautpankreas-Elastase hat. Das beruht darauf, dass das humane 
Genom sechs Elastase-Gene besitzt mit strukturell ähnlichen ElastaseProteinen: Elastase-1 (Keratinozyten), Elastase-2 (Neutrophile), Elastase$2 A,-2 B,-3 A$ und $-3 B$ (alle aus dem Pankreas). Das menschliche PankreasElastase-1-Gen wird nicht transkribiert, und bis heute wurde eine Elastase-1-Expression nur in den Keratinozyten der Haut, aber nicht im Pankreas festgestellt. Elastase-3B, andererseits, hat nur eine geringe Elastin (= Skleroprotein) spaltende Aktivität, die möglicherweise andere Verdauungsaufgaben im Darm hat. Die rekombinante Elastase-2B besitzt nach neueren Untersuchungen keinerlei proteolytische Aktivität (Szepessy u. Sahin-Tóth 2006).

Die unterschiedlichen Ergebnisse dieser Untersuchungen der exokrinen Pankreasinsuffizienz könnten auf der unterschiedlichen Messweise der beiden Elastase-Tests beruhen. Während der monoklonale Antikörper der Elastase-1-ELISA-Bestimmung der Firma ScheBo-Biotech tatsächlich gegen die Elastase-2 gerichtet ist, beruht der Test der Firma Bioserv Diagnostics auf einer Mischung polyklonaler Seren mit besonderer Spezifität für Elastase-3A. Die unterschiedliche Spezifität gegenüber spezifischen Pankreas-Elastasen könnte die hier beobachteten Unterschiede erklären. Bis heute wurden die Unterschiede der Exprimierung, der Sekretion und der spezifischen Funktion der Pankreas-Elastasen 2 und 3 beim Menschen noch nicht untersucht, und ihr spezifischer prognostischer Wert bei der Beurteilung der exokrinen Pankreasfunktion bedarf weiterer Untersuchungen.

In dieser letztlich noch nicht geklärten Situation wurde beschlossen, bei der Untersuchung der exokrinen Pankreasfunktion bei niereninsuffizienten Patienten beide Tests einzusetzen und auch Patienten, bei denen nur ein oder zwei Elastase-Tests zu einem pathologischen Ergebnis führten, als exokrin pankreasinsuffizient einzustufen. 


\subsection{Diagnostik einer Diarrhoe und Steatorrhoe}

Eine Diarrhoe liegt vor, wenn die Stuhlfrequenz mehr als dreimal pro Tag oder das Stuhlgewicht mehr als $200 \mathrm{~g} /$ Tag beträgt. Die Stuhlkonsistenz ist vermindert oder flüssig (Wassergehalt mehr als $80 \%$ ). Alle drei Parameter werden durch den Ballaststoffgehalt der Nahrung, durch Medikamente, Stress und Extremsport (zum Beispiel Marathonlauf) beeinflusst (Lankisch et al. 2006).

Zur Diagnostik der Diarrhoe werden üblicherweise - und das ist auch in dieser Untersuchung geschehen - die Patienten gebeten, ihren Stuhlgang über drei Tage in Töpfen zu sammeln. Das Stuhlgewicht wird durch Wiegen ermittelt, eine Diarrhoe ist als Stuhlgewicht von $>200 \mathrm{~g} /$ Tag definiert. Stuhlgewichte zwischen 200 und $300 \mathrm{~g}$ werden in der Regel als leichte bis mäßig schwere, Stuhlgewichte über $300 \mathrm{~g}$ als schwere Diarrhoe bezeichnet.

Zur Messung der Stuhlfettausscheidung wird ebenfalls der Stuhlgang, der zur Diagnostik der Diarrhoe an drei aufeinander folgenden Tagen gesammelt wurde, genutzt. Die Messung des Stuhlfettes erfolgt entweder nach der van-de-Kamer-Methode (Van de Kamer et al. 1949) oder mithilfe der hier benutzten Methode der physikalischen Nah-Infrarot-ReflexionsSpektrografie (NIRS). Eine Steatorrhoe liegt dann vor, wenn die tägliche Stuhlfettausscheidung auf $>7 \mathrm{~g} / \mathrm{Tag}$ erhöht ist. Eine Stuhlfettausscheidung zwischen 7 und $15 \mathrm{~g}$ wird als leichte bis mäßig schwere Steatorrhoe, eine Stuhlfettausscheidung $>15 \mathrm{~g}$ als schwere, in der Regel pankreasenzymsubstitutionsbedürftige Steatorrhoe bezeichnet.

Eine Steatorrhoe beweist eine Störung digestiv-resorptiver Funktionen proximal des Kolons. Differenzialdiagnostisch muss an eine Erkrankung des Dünndarms oder des Pankreas, an eine Gallensäurestoffwechselstörung, eine Erkrankung des lymphatischen Resorptionsweges der Neutralfette oder aber an endokrine Erkrankungen gedacht werden (Lembcke et al. 1994; Lankisch et al. 2006; Camilleri u. Murray 2008). 
Zur Diagnostik einer solchen Steatorrhoe sind in der Regel folgende Untersuchungen sinnvoll:

1. Zum Nachweis oder Ausschluss einer schweren exokrinen Pankreasinsuffizienz dienen direkte oder indirekte Pankreasfunktionstests. Zum Beispiel der SPT mit seinen Modifikationen oder die fäkale Elastase-1- bzw. Chymotrypsinbestimmung im Stuhl.

2. Zum Ausschluss einer strukturellen Dünndarmerkrankung ist eine Ösophagogastroduodenoskopie mit tiefen Dünndarmbiopsien, zum Beispiel zum Nachweis einer einheimischen Sprue beziehungsweise einer Lamblienbesiedlung notwendig. Ferner muss eine Ileokoloskopie mit Biopsien aus dem terminalen Ileum zum Nachweis eines Gallensäureverlustsyndroms bei chronisch-entzündlicher Darmerkrankung erfolgen.

3. Zum Nachweis endokriner Erkrankungen sollte eine Chromogranin-ABestimmung, eine 5-Hydroxyindolessigsäure-Messung (Karzinoid?), eine Gastrinbestimmung (Zollinger-Ellison-Syndrom?) und/oder ein $\mathrm{H}_{2}$-Glukose-Atemtest (bakterielle Besiedlung bei autonomer diabetischer Neuropathie?) durchgeführt werden (Lankisch et al. 2006).

Die Durchführung all dieser Untersuchungen hätte die hier in Lüneburg zur Verfügung stehenden Möglichkeiten apparativ und kostenmäßig überschritten. Deshalb beschränkt sich diese Untersuchung darauf, Patienten mit Erkrankungen beziehungsweise Zuständen auszuschließen, die in der Regel zu einer Steatorrhoe führen, nämlich ein Zustand nach akuter Pankreatitis, eine bereits diagnostizierte chronische Pankreatitis, eine exokrine Pankreasinsuffizienz, ein Zustand nach Resektion des Magens beziehungsweise nach Teilresektion des Dünndarms, die anamnestische Angabe einer chronisch-entzündlichen Darmerkrankung sowie eine Hyperthyreose. Ausgeschlossen wurden auch Patienten mit unklaren Oberbauchbeschwerden, deren Ursache eine bislang noch nicht erkannte Pankreaserkrankung hätte sein können. 


\subsection{Das Pankreas bei Niereninsuffizienz}

4.3.1. Morphologische Untersuchungen des Pankreas bei Niereninsuffizienz

Frühere pathologisch-anatomische Untersuchungen bei verstorbenen urämischen Patienten zeigten bei bis zu 60\% der Fälle Veränderungen im Pankreas, die manchmal, jedoch nicht immer, als Ausdruck einer chronischen Pankreatitis angesehen wurden.

Baggenstoss (1948) untersuchte histologisch das Pankreas von 85 konsekutiven Patienten mit chronischer Glomerulonephritis mit Urämie, 85 konsekutiven Patienten mit Hypertonie und Urämie und 100 weiteren konsekutiven Patienten mit Urämie, hervorgerufen durch Hydronephrose, Pyelonephritis oder extrarenale Faktoren. Dilatation der Azini unterschiedlichen Ausmaßes, Abflachung des Epithelsaumes und Eindickung des Sekretes fanden sich bei 33 (39\%), 36 (42\%) beziehungsweise 52 (52\%) dieser Patienten, aber auch bei 40 (20\%) von 200 Patienten, die zu Lebzeiten nicht an einer Urämie gelitten hatten. Die Diagnose einer chronischen Pankreatitis wurde bei den genannten Patienten jedoch nicht gestellt.

Avram (1977) fand Pankreasveränderungen bei 12 (57\%) von 21 autopsierten Hämodialyse-Patienten und sieben (12\%) von 60 Patienten, die zu Lebzeiten nicht an Nieren- und/oder Pankreaserkrankungen gelitten hatten.

Avram u. Iancu (1982) fanden bei 15 (71\%) von 21 verstorbenen Hämodialyse-Patienten, aber bei keinem von 60 Patienten ohne Niereninsuffizienz histologische Veränderungen im Sinne einer chronischen Pankreatitis. Die Veränderungen korrelierten mit einem hohen Parathormonspiegel, dessen Rolle als multisystemisches urämisches Toxin diskutiert wurde. 
Vaziri et al. (1987) berichteten über Pankreasveränderungen bei 47 $(60 \%)$ von 78 verstorbenen Hämodialyse-Patienten. Die häufigste Ursache war eine Pankreatitis, die bei 22 (28\%) Patienten nachgewiesen wurde.

Araki et al. (1992) fanden histologische Hinweise auf eine Pankreatitis bei $14(52 \%)$ von 27 Hämodialyse-Patienten im Vergleich zu vier (15\%) von 27 Kontrollpatienten. Die Pankreatitis wurde bei zwölf (44\%) der 14 Patienten als chronisch eingestuft, als subakut bei einem und als akut bei einem weiteren (jeweils 4\%). Bei den untersuchten 27 Kontrollpatienten fand sich eine chronische Pankreatitis bei drei (11\%), eine subakute Pankreatitis bei einem (4\%) Patienten.

Ferner untersuchte die Gruppe zwölf weitere Patienten mit terminaler Niereninsuffizienz nach Sekretingabe und fand bei nur einem Patienten einen Anstieg der Gesamt- beziehungsweise Pankreasisoamylase.

Die Autoren folgerten, dass die bei Patienten mit terminaler Niereninsuffizienz häufig beobachteten Pankreasisoamylase-Anstiege nicht auf die histologisch diagnostizierte chronische Pankreatitis bei diesen Patienten zurückzuführen seien.

\subsubsection{Funktionsuntersuchungen des Pankreas bei Niereninsuffizienz}

Eine Reihe von Autoren hat in den 60er, 70er und $80 \mathrm{er}$ Jahren des letzten Jahrhunderts untersucht, ob die nach den geschilderten histologischen Untersuchungen so häufigen Pankreasveränderungen bei niereninsuffizienten Patienten Auswirkungen auf die Bauchspeicheldrüsenfunktion haben. Es gibt allerdings keine Studie, in der gleichzeitig die Pankreasfunktion und die Morphologie des Pankreas untersucht wurden. In keiner Untersuchung (Tabelle 12) wurde überprüft, ob die gemessene Funktionseinbuße tatsächlich morphologischen Veränderungen des Pankreas entsprach. Wahrscheinlich ist dies darauf zurückzuführen, dass zum Zeitpunkt der Untersuchung bildgebende Verfahren wie Ultraschall, Computertomografie, Endosonografie oder Magnetresonanz-Untersuchungen noch nicht bekannt waren oder noch nicht überall zur Anwendung kamen. 
In keiner Untersuchung aber wurde versucht, festzustellen, ob der beobachtete exokrine Pankreasfunktionsverlust eventuell eine lebenslange teure Pankreasenzymsubstitution erforderlich gemacht hätte. Das bedeutet, dass bei keiner dieser Untersuchungen eine Stuhlgewichts- und Stuhlfettbestimmung erfolgte. Dies ist zum ersten Mal in der hier vorgelegten Untersuchung geschehen.

Vier Untersuchergruppen (Wittich et al. 1968; Bartos et al. 1970; Gerhardt et al. 1974; Poll et al. 1979;) fanden, dass eine normale Pankreasfunktion nur bei $19-46 \%$ der untersuchten Patienten mit chronischer Niereninsuffizienz vorlag. Die Art der Funktionseinbuße war jedoch inhomogen: normale beziehungsweise reduzierte Bikarbonatkonzentration, normale beziehungsweise reduzierte Enzymsekretion. Drei weitere Untersuchungen (Otte et al. 1975; Dinoso et al. 1982; Owyang et al. 1982) machten keine Angaben über einzelne Patienten, sondern berichteten nur über die von innen untersuchten Patienten als Gruppe. Auch in diesen Untersuchungen fand sich ein exokriner Pankreasfunktionsverlust bei Patienten mit Niereninsuffizienz (Tabelle 12).

In keiner der in Tabelle 12 gezeigten Untersuchungen wurde überprüft, ob bei einer eventuellen Enzymsekretionsminderung diese in einem enzymsubstitutionsbedürftigen Bereich lag. Immerhin haben Wittich et al. (1968) und Sachs et al. (1983) eine Verminderung der Lipasesekretion gefunden, die möglicherweise zu einer Steatorrhoe hätte führen können.

Zwei Arbeitsgruppen wiesen auf die besondere Bedeutung der verminderten Bikarbonatkonzentration hin. Bartos et al. (1970) glaubten, dass durch die verminderte Bikarbonatkonzentration eine Veränderung des alkalischen Milieus im Duodenum zum Sauren hin bewirkt werde, womit die Entstehung von Ulcera duodeni beziehungsweise Blutungen aus diesem Bereich erklärt werden könnten. Beides ist bei Hämodialyse-Patienten häufig (Shepherd et al. 1973; Wasse et al. 2003; Furkert et al. 2008).

Dinoso et al. (1982) fanden eine Magensäure-Hypersekretion in Verbindung mit einer Bikarbonat-Hyposekretion, die verantwortlich sein könnte für die bereits geschilderte Häufigkeit gastrointestinaler beziehungsweise speziell duodenaler Erkrankungen bei Hämodialyse-Patienten. 
Tabelle 12

Pankreasfunktionsuntersuchungen (SPT, Sekretin-Pankreozymin-Test; SMT, Sekretin-Methacholin-Test; ST, Sekretin-Test; CCK, Cholecystokinin-Test) bei chronischer Niereninsuffizienz, ergänzt beziehungsweise modifiziert nach Abu-Alfa et al. (Abu-Alfa et al. 1988)

\begin{tabular}{|c|c|c|c|c|c|c|c|}
\hline Autoren & $\begin{array}{l}\text { Anzahl der } \\
\text { untersuchten } \\
\text { Patienten }\end{array}$ & $\begin{array}{c}\text { Pankreas- } \\
\text { funktions- } \\
\text { test }\end{array}$ & $\begin{array}{c}\text { Patienten mit } \\
\text { normalem } \\
\text { Testergebnis }\end{array}$ & $\begin{array}{c}\text { Bikarbonat- } \\
\text { Konzentration }\end{array}$ & Amylase & Lipase & Trypsin \\
\hline Wittich et al. (1968) & $25^{1}$ & SPT & $6(24 \%)$ & Normal & $\downarrow$ & $\downarrow$ & Normal \\
\hline Bartos et al. (1970) & $16^{1}$ & SPT & $3(19 \%)$ & $\downarrow$ & Normal & Normal & - \\
\hline Gerhardt et al. (1974) & 24 & SMT & $13(46 \%)$ & Normal & Normal & - & Normal \\
\hline Otte et al. (1975) & $15^{2}$ & SPT & - & Normal & $\downarrow$ & Normal & Normal \\
\hline Poll et al. (1979) & $46^{1}$ & SPT & $18(39 \%)$ & $\downarrow$ & $\downarrow$ & - & - \\
\hline Dinoso et al. (1982) & 25 & ST & - & $\downarrow$ & - & - & - \\
\hline Owyang et al. (1982) & $8^{3}$ & $\mathrm{CCK}$ & - & - & - & Normal & $\uparrow$ \\
\hline Sachs et al. (1983) & $8^{3}$ & SPT & - & Normal & $\downarrow$ & $\downarrow$ & Normal \\
\hline
\end{tabular}

${ }^{1}$ Patienten mit Niereninsuffizienz unterschiedlichen Schweregrades und unterschiedlicher Behandlung

${ }^{2} \mathrm{Hämo}$ - und Peritonealdialyse-Patienten

${ }^{3}$ Hämodialyse-Patienten 
Ein Zusammenhang mit den unterschiedlichen Ursachen einer terminalen Niereninsuffizienz wurde nur einmal untersucht. Wittich et al. (1968) fanden nämlich, dass interstitielle Nephritiden beziehungsweise Pyelonephritiden häufiger zu einer Pankreasbeteiligung prädisponierten als andere Ursachen der Niereninsuffizienz. Dies entspricht nicht den in dieser Untersuchung gemachten Erfahrungen, die Unterschiede zwischen den beiden Untersuchungen sind jedoch nicht zu erklären.

Stuhlenzymmessungen zur Diagnose einer exokrinen Pankreasinsuffizienz bei terminaler Niereninsuffizienz sind nur selten durchgeführt worden, und zwar zweimal von der gleichen Arbeitsgruppe (Ventrucci et al. 1995; 2000).

Ventrucci et al. (1995) fanden pathologische Chymotrypsinwerte seinerzeit bei $9(32 \%)$ von 28 Hämodialyse-Patienten. Mehrere Jahre später untersuchte die gleiche Arbeitsgruppe (Ventrucci et al. 2000) 25 Hämodialyse-Patienten ohne klinischen Hinweis auf eine Pankreaserkrankung sowie 25 gesunde Kontrollpatienten mithilfe der fäkalen Elastase-1-Messung und der Chymotrypsinbestimmung. Pathologische Chymotrypsinwerte fanden sich bei $10(40 \%)$ von 25 Hämodialyse-Patienten. Pathologische Elastase1-Werte lagen bei 12 (48\%) dieser Patienten vor. Davon hatten 6 (24\%) Werte von $<100 \mu \mathrm{g} / \mathrm{g}$ Stuhl. Eine Stuhlfettanalyse wurde in dieser Untersuchung nicht durchgeführt.

Wizemann u. Benz (1978) untersuchten 148 Patienten mit einer chronischen Niereninsuffizienz (Serum-Kreatinin $>7 \mathrm{mg} / \%$ ), die in eine Gruppe mit kompensierter Retention und einer weiteren Gruppe von HämodialysePatienten gegliedert wurden. Insgesamt sechs (24\%) der 26 niereninsuffizienten und drei $(21 \%)$ der 14 Hämodialyse-Patienten hatten ein erniedrigtes Chymotrypsin.

Aguilera et al. (2003) fanden bei 39 (80\%) von 49 PeritonealdialysePatienten ebenfalls ein erniedrigtes Chymotrypsin. Allerdings waren prokinetische Medikamente bei acht Patienten nicht abgesetzt worden, so dass 
die Chymotrypsinwerte durch den Durchfall beziehungsweise die Verdünnung des Stuhls hätten falsch erniedrigt sein können.

Die Ergebnisse der hier vorgelegten Untersuchung zeigen, dass eine exokrine Pankreasinsuffizienz bei Hämodialyse-Patienten, gemessen mit der ELISA-Methode, nicht häufig und im Vorgriff auf das nächste Kapitel nicht substitutionsbedürftig ist. Die Ergebnisse überraschen ferner dadurch, dass beide Elastase-Messmethoden in ihrem pathologischen Ergebnis nicht überein stimmen. Die Ursache, warum der Anteil Pankreasinsuffizienter bei Patienten mit Niereninsuffizienz so deutlich abgenommen hat, hat mindestens einen sicheren und einen wahrscheinlichen Grund.

1. Der sichere Grund ist, dass die hier vorgelegte Studie wahrscheinlich mehr Patienten mit exokriner Pankreasinsuffizienz nachgewiesen hätte, wenn der SPT beziehungsweise eine seiner Modifikationen zur Diagnostik einer exokrinen Pankreasinsuffizienz herangezogen worden wären. Es ist jedoch zurzeit davon auszugehen, dass diese Testmöglichkeit in Deutschland nur noch sehr selten - wenn überhaupt - und zumindest nicht in Lüneburg und Göttingen verfügbar ist und als Goldstandard für die Überprüfung der Pankreasfunktion jetzt die fäkale Elastase-1-Messung zu gelten hat. Diese ist jedoch - wie dargelegt nicht ausreichend sensitiv für den Nachweis einer leichten bis mäßig schwer ausgeprägten exokrinen Pankreasinsuffizienz. Dies bedeutet allerdings auch, dass bei den jetzt entdeckten Patienten keine schwere exokrine Pankreasinsuffizienz vorliegt, die mit Pankreasenzymen lebenslang substituiert werden müsste. Die bei $10 \%$ unserer Patienten beobachtete exokrine Pankreasinsuffizienz ist also kein klinisch relevanter Befund.

2. Ein wahrscheinlicher Grund liegt in dem unterschiedlichen allgemeinen Ernährungszustand der Dialyse-Patienten damals und heute. In den 60er und 70er Jahren standen nicht ausreichend Dialyseplätze zur Verfügung, so dass Patienten mit einer Niereninsuffizienz erst spät in ein Dialyseprogramm aufgenommen werden konnten. Es ist davon aus- 
zugehen, dass sie sich dann in einem schlechten Ernährungszustand befanden. Schlechte Ernährungszustände wiederum erklären eine exokrine Pankreasinsuffizienz.

Die im Folgenden geschilderten Beispiele für den Einfluss der Ernährung auf die exokrine Pankreasfunktion entstanden nicht bei Untersuchungen an niereninsuffizienten Patienten, könnten aber vielleicht analog zur Argumentation genutzt werden.

Wenn Patienten freiwillig hungern, das heißt zum Beispiel über 20 Tage eine Nulldiät durchführen, nehmen Volumen, Bikarbonat-, Trypsin- und Amylase-Sekretion bei Funktionstests vor und nach dem Fasten deutlich ab (Fölsch et al. 1984).

Bei Essstörungen nimmt nicht nur das Gewicht des Patienten, sondern auch das Volumen seiner Bauchspeicheldrüse ab. Die Pankreasgröße korreliert nach Untersuchungen von Cuntz et al. (2000) hoch signifikant mit dem BMI. Daraus ist indirekt zu folgern, dass mit der abnehmenden Größe an Volumen sich der Enzymgehalt und damit die exokrine Pankreasfunktion reduzierten.

Mehrere Untersuchungen an Eiweißmangelerkrankten in Indien und Westafrika zeigten eine reduzierte exokrine Pankreasfunktion, die sich nach einer entsprechenden Diät besserte beziehungsweise normalisierte (Tandon et al. 1969, 1970; Kumar et al. 1975; Descos et al. 1977; Sauniere u. Sarles 1988).

\subsection{Diarrhoe und Steatorrhoe bei Niereninsuffizienz}

Wizemann u. Benz (1978), Sachs et al. (1983) sowie Aguilera et al. (2003) haben auch die Stuhlfettausscheidung bei Patienten mit terminaler Niereninsuffizienz gemessen.

Die erste Gruppe (Wizemann u. Benz 1978) fand bei Patienten mit höhergradiger Niereninsuffizienz, das heißt einem Serum-Kreatinin von $>7$ $\mathrm{mg} \%$, eine deutliche pathologische Stuhlfettausscheidung, die im Mittel 
bei $12 \mathrm{~g} /$ Tag lag. Ein signifikanter Unterschied zwischen den noch nicht dialysepflichtigen und den dialysepflichtigen Patienten bestand nicht. Auch korrelierte die tägliche Stuhlfettausscheidung nicht mit dem urämischen Intoxikationsgrad, bezogen auf das Serum-Kreatinin. Die Autoren versuchten, die beobachtete Steatorrhoe zu normalisieren, indem sie fünf Patienten täglich ein Pankreasenzympräparat zuführten und darunter einen deutlichen Rückgang der Stuhlfettausscheidung sahen. Die Autoren stellten jedoch diese fünf Fälle nicht im Einzelnen dar und erklärten auch nicht, ob bei innen das Chymotrypsin im Stuhl erniedrigt gewesen war. In dieser Studie bestand kein Zusammenhang zwischen mithilfe von Elastase-1-Messungen gefundener exokriner Pankreasinsuffizienz und einer Steatorrhoe, so dass eine Therapie mit Pankreasenzympräparaten nicht wirksam sein konnte.

Sachs et al. (1983) berichteten über eine Steatorrhoe bei ihren Patienten mit Niereninsuffizienz (vier [50\%] von acht), wobei diese jedoch nicht im Zusammenhang mit der verminderten Lipasesekretion gesehen wurde.

Aguilera et al. (2003) fanden bei 20 (41\%) der 49 Patienten eine Steatorrhoe (Stuhlfett $>7 \mathrm{~g} / \mathrm{Tag}$ ). Sie berichteten darüber hinaus eine negative Korrelation zum Chymotrypsin, das heißt, ein niedriges Chymotrypsin war mit erhöhtem Fettgehalt verbunden. Auch in diesem Fall erschwert die Zugabe von prokinetischen Medikamenten die Beurteilung, ebenso wie die fehlende Angabe der Einzelwerte. Es wäre interessant gewesen, festzustellen, wie viele Patienten ein normales Chymotrypsin und trotzdem eine Steatorrhoe hatten.

Die hier vorgelegte Untersuchung konzentrierte sich auf die Beziehung der exokrinen Pankreasfunktion zur Niereninsuffizienz. Die weitere Differenzialdiagnostik einer Diarrhoe beziehungsweise Steatorrhoe konnte in dieser Arbeit nicht berücksichtigt werden. Bei der Diarrhoe waren alle akuten Fälle ausgeschlossen, das Stuhlgewicht war in den hier beschriebenen neun Fällen nur leicht und nicht therapiebedürftig erhöht. 
Ebenso lag die Steatorrhoe nicht in einem nach den Leitlinien für die chronische Pankreatitis (Mössner et al. 1998) geltenden therapiebedürftigen Bereich. Eine chronische Pankreatitis, eine Schilddrüsenüberfunktion, ein Zustand nach Magenresektion mit konsekutiver postzibaler Asynchronie oder ein Zustand nach Dünndarmresektion in der Anamnese, also klinische Situationen, die eine Steatorrhoe bewirken, führten zum Ausschluss der betroffenen Patienten von dieser Studie.

Fünf Patienten mit gleichzeitiger leichter bis mäßig schwerer Diarrhoe und Steatorrhoe wurden alle, ebenso wie ein weiterer Patient mit leichtem bis mäßig schwerem Durchfall, mit einem Phosphatbinderpräparat therapiert. Die fünf weiteren Patienten mit leichter bis mäßig schwerer Steatorrhoe sowie drei Patienten mit leichter bis mäßig schwerer Diarrhoe nahmen keine entsprechenden Medikamente. Phosphatbinder binden auch Gallensäuren und verhindern ihren Einschluss in den enteropathischen Kreislauf. Dadurch können Gallensäuren im Duodenum bei der Mizellenbildung, einer Voraussetzung für die Fettresorption, fehlen, was eine Steatorrhoe erklären könnte. Möglicherweise führen Gallensäuren, die nicht im terminalen Ileum rückresorbiert werden, im unteren Dünndarm beziehungsweise im Kolon zu wässrigen Diarrhoen (kompensiertes Gallensäureverlustsyndrom) beziehungsweise zu Diarrhoe und Steatorrhoe (dekompensiertes Gallensäureverlustsyndrom). Eine sichere Erklärung für das Auftreten von Diarrhoe und Steatorrhoe ist das jedoch nicht.

Chronische Durchfälle können bei Nierenversagen noch eine Reihe anderer Ursachen haben, die in dieser Studie jedoch nicht berücksichtigt wurden. Ein chronisches Nierenversagen führt zu einer Reihe von klinischen, funktionellen und histopathologischen Veränderungen im Gastrointestinaltrakt einschließlich Reduktion der Höhe der Villi, Vermehrung der Kryptentiefe, einer Beeinträchtigung der intestinalen Permeabilität sowie Veränderungen der Disaccharidasen- und Dipeptidasen-Aktivitäten und resorptiven Funktionen (Denneberg et al. 1974; Goldstein et al. 1981; Arvanitakis et al. 1988; Magnusson et al. 1991; Stein et al. 1994). Eine 
besondere Rolle kommt dabei der Plasma-Diaminooxidase-Aktivität zu. Dieses für den Polyaminstoffwechsel wichtige Enzym ist in den Enterozyten lokalisiert und nimmt vom proximalen Dünndarm zum Ileum hin zu. Patienten mit einer Schleimhautatrophie im Dünndarm, wie sie zum Beispiel bei chronisch entzündlichen Darmerkrankungen, einheimischer Sprue und einem Hungerzustand bei Anorexia nervosa auftritt, haben signifikant niedrigere PostheparindiaminoxidaseAktivitäten.

Stein et al. (1994) konnten eine verminderte Diaminoxidase-Freisetzung bei Patienten mit chronischer Niereninsuffizienz zeigen, was für eine mukosale Störung des Dünndarms bei diesen Patienten spricht.

Eine solche Störung könnte verantwortlich sein für die bei der hier vorgelegten Untersuchung beobachtete Diarrhoe und Steatorrhoe.

\subsection{Schlussfolgerungen}

Eine exokrine Pankreasinsuffizienz bei Hämodialyse-Patienten mit terminaler Niereninsuffizienz tritt nach den hier vorgelegten Ergebnissen nicht selten auf. Sie ist jedoch kompensiert und nicht dekompensiert, das heißt, nicht verbunden mit einer (pankreatogenen) Steatorrhoe. Somit bedarf sie keiner lebenslangen und teuren Pankreasenzymsubstitution. Die hier beobachtete exokrine Pankreasinsuffizienz stellt also für den Kliniker kein therapierelevantes Problem dar.

Von klinischer Relevanz könnten jedoch die hier beobachtete ebenfalls nicht seltene Diarrhoe und vor allem die Steatorrhoe sein. Gängige Ursachen einer Steatorrhoe waren Ausschlusskriterien für diese Untersuchung. Die Möglichkeiten beziehungsweise Notwendigkeiten weiterer Untersuchungen bei unklarer Diarrhoe oder Steatorrhoe sind damit jedoch keinesfalls erschöpft. Solche Untersuchungen sollten folgen, wobei vor allem eine Untersuchung des Dünndarms und seiner Resorption bei Patienten mit terminaler Niereninsuffizienz von Interesse sein dürfte. Diese Untersuchung wird als sinnvoll erachtet, weil eine unbehandelte 
Steatorrhoe sicherlich ein weiterer Risikofaktor für die bei chronischer Niereninsuffizienz nicht selten auftretende Osteoporose ist.

Die exokrine Pankreasinsuffizienz war nicht korreliert mit dem Alter, dem BMI, der durchschnittlichen Dialysedauer und der Ursache des Nierenversagens.

Eine leichte bis mäßig schwere Diarrhoe und Steatorrhoe fanden sich in neun (18\%) beziehungsweise zehn (20\%) Fällen, wobei bei fünf (insgesamt $10 \%$ ) dieser Patienten sowohl eine Diarrhoe als auch eine Steatorrhoe vorlagen. Alle Patienten mit Diarrhoe und Steatorrhoe sowie ein Patient mit leichter bis mäßig schwerer Diarrhoe wurden mit einem Phosphatbinder behandelt, so dass ein Teil der pathologischen Befunde möglicherweise auf das Medikament zurückzuführen ist. Andere Ursachen der Diarrhoe und/oder Steatorrhoe konnten im Rahmen dieser Untersuchung nicht abgeklärt werden. Weitere Untersuchungen wären jedoch sehr sinnvoll, weil eine unbehandelte Steatorrhoe sicherlich ein zusätzlicher Risikofaktor für die bei chronischer Niereninsuffizienz nicht selten auftretende Osteoporose ist. 


\section{Zusammenfassung}

1. Frühere Untersuchungen aus den $60 \mathrm{er}, 70 \mathrm{er}$ und $80 \mathrm{er}$ Jahren des letzten Jahrhunderts zeigten, dass ein hoher Prozentsatz von Patienten mit terminaler Niereninsuffizienz vor und unter dem Einsatz von Dialyseverfahren nach den Ergebnissen des Sekretin-Pankreozym-Tests (SPT) beziehungsweise seiner Modifikationen unter einer exokrinen Pankreasinsuffizienz leiden. Es wurde bislang jedoch nicht überprüft, ob es sich hierbei um eine dekompensierte exokrine Pankreasinsuffizienz handelt, also ob eine Steatorrhoe vorliegt, die einer Pankreasenzymsubstitution bedarf.

2. Der SPT, der Goldstandard der exokrinen Pankreasfunktionsprüfung, wird jedoch weltweit praktisch nicht mehr durchgeführt, da es sich um einen invasiven, technisch aufwendigen und kostspieligen Test handelt. Als Ersatz des SPT beziehungsweise seiner Modifikationen wird nun ein indirekter exokriner Pankreasfunktionstest, die Elastase-1-Messung im Stuhl, angewendet. Hierzu stehen zwei verschiedene Messmethoden zur Verfügung. Die erste Methode verwendet einen monoklonalen Antikörper, der auf einem enzymgebundenen Immunosorbit-Assay (ELISA) (ScheBo-Biotech, Wittenberg) basiert, die zweite Methode (Bioserv Diagnostics, Rostock) benutzt einen polyklonalen ELISA.

3. Ziel dieser Untersuchung war es, bei 50 Hämodialyse-Patienten der Nephrologischen Praxis am Städtischen Klinikum Lüneburg mit Hilfe beider Elastase-1-Messungen festzustellen, wie häufig bei ihnen eine exokrine Pankreasinsuffizienz besteht. Ferner sollte mithilfe der Stuhlgewichts- und Stuhlfettanalyse ermittelt werden, wie häufig darüber hinaus eine Diarrhoe beziehungsweise Steatorrhoe vorliegt.

4. Bei keinem der Patienten waren früher akute Pankreatitiden abgelaufen oder war zu keinem Zeitpunkt eine chronische Pankreatitis beziehungsweise eine exokrine Pankreasinsuffizienz mit bekannter oder unbekannter Ätiologie festgestellt worden. Ebenso waren bei keinem der Patienten Oberbauchoperationen mit Resektion des Magens 
und/oder von Dünndarmanteilen durchgeführt worden, bei keinem bestanden früher oder zum Zeitpunkt der Untersuchung unklare Oberbauchbeschwerden, die den Verdacht auf eine chronische Pankreatitis hätten erwecken können. Bei allen war die TSH-(Thyreoidea stimulierendes Hormon-)Bestimmung normal, so dass eine Diarrhoe beziehungsweise Steatorrhoe auf dem Boden einer Hyperthyreose ausgeschlossen war. Eine sorgfältige Ultraschalluntersuchung ergab ferner bei keinem Patienten Hinweise auf eine Pankreaserkrankung oder insbesondere auf eine chronische Pankreatitis.

5. Eine exokrine Pankreasinsuffizienz wurde als sicher angesehen, wenn eine der beiden Messmethoden oder beide pathologisch ausfielen. Lagen die Messwerte zwischen 100 und $200 \mu \mathrm{g} / \mathrm{g}$ Stuhl, wurde eine leichte bis mäßig schwere, darunter eine schwere enzymsubstitutionsbedürftige exokrine Pankreasinsuffizienz angenommen.

6. Nach dieser Definition bestand bei fünf (10\%) der Patienten eine exokrine, jedoch nicht therapiebedürftige Pankreasinsuffizienz. Die Pankreasinsuffizienz war nicht signifikant korreliert mit dem Alter, dem Geschlecht, dem BMI, der Dialysedauer, der Ursache der Niereninsuffizienz und dem Stuhlgewicht beziehungsweise Stuhlfettgehalt der Patienten.

7. Neun (18\%) Patienten hatten eine Diarrhoe (>200 g Stuhlgewicht/ Tag), zehn (20\%) hatten eine Steatorrhoe ( $>7 \mathrm{~g}$ Fettausscheidung/ Tag). Bei fünf dieser Patienten lagen gleichzeitig eine Diarrhoe und eine Steatorrhoe vor. In allen Fällen handelte es sich um eine leichte bis mäßig schwere Diarrhoe beziehungsweise Steatorrhoe bei Stuhlgewichten zwischen 200-300 g/Tag beziehungsweise einem Stuhlfettgehalt zwischen $7-15 \mathrm{~g} / \mathrm{Tag}$. Alle fünf Patienten mit gleichzeitiger Diarrhoe und Steatorrhoe sowie ein Patient mit Diarrhoe wurden mit einem Phosphatbinder behandelt, der möglicherweise über eine Bindung der Gallensäuren eine Verminderung der Gallensäuren bei der Mizellenbildung und somit eine Steatorrhoe bewirkte. 
8. Eine exokrine Pankreasinsuffizienz bei Patienten mit terminaler Niereninsuffizienz ist also kein seltenes Ereignis. Sie ist jedoch nicht therapiebedürftig, das heißt, eine lebenslange teure Pankreasenzymsubstitution ist nicht notwendig. Im Vergleich zu früheren Untersuchungen, die eine exokrine Pankreasinsuffizienz in bis zu $60 \%$ der Patienten mit Niereninsuffizienz angaben, liegt die jetzt festgestellte Häufigkeit deutlich niedriger. Ein indirekter Pankreasfunktionstest, wie die Elastase-1-Messung im Stuhl, hat eine sicherlich deutlich niedrigere Sensitivität in der Erkennung einer leichten bis mäßig schweren Insuffizienz als der Goldstandard, der SPT und seine Modifikationen. Das bedeutet, dass in dieser Studie möglicherweise Patienten mit einer leichten bis mäßig schweren Pankreasinsuffizienz nicht erkannt wurden. Vom klinischen Standpunkt aus ist dies jedoch nicht bedeutsam, denn diese Patienten hätten auch keiner Pankreasenzymsubstitution bedurft. Eine weitere Ursache für den hier festgestellten niedrigen Anteil pankreasinsuffizienter Patienten könnte der jetzt deutlich bessere Ernährungszustand von niereninsuffizienten Patienten sein. Der in den 60er, 70er und 80er Jahren bei Niereninsuffizienten, die erst spät einem Dialyseverfahren zugeführt werden konnten, häufig vorliegende schlechte Allgemein- und Ernährungszustand war sicherlich eine Ursache für die seinerzeit höhere Pankreasinsuffizienzrate.

9. Ebenfalls nicht selten ist eine Diarrhoe und/oder Steatorrhoe bei Patienten mit terminaler Niereninsuffizienz unter einer HämodialyseTherapie. Wesentliche Ursachen einer Steatorrhoe, wie eine exokrine Pankreasinsuffizienz, Folgezustände nach Magen- und Dünndarmteilresektion, chronisch-entzündliche Darmerkrankungen und eine Hyperthyreoidose sowie akute Diarrhoezustände, lagen bei den beobachteten Patienten nicht vor. Weitere Untersuchungen sollten klären, welche Ursache insbesondere die Steatorrhoe hat, damit gegebenenfalls durch eine Therapie die Komplikationen einer erhöhten Stuhlfettausscheidung, wie zum Beispiel Osteoporose, bei Niereninsuffizienz verhindert werden können. 


\section{Literaturverzeichnis}

Abu-Alfa A, Ivanovich P, Mujais SK (1988): Uremic exocrine pancreopathy. Nephron 48: 94-100

Aguilera A, Bajo A, Espinoza M, Olveira A, Paiva AM, Codoceo R, García P, Sánchez S, Celadilla O, Castöro MJ, Selgas R (2003): Gastrointestinal and pancreatitic function in peritoneal dialysis: their relationship with malnutrition and peritoneal membrane abnormalities. Am J Kidney Dis 42: 787-796

Amann ST, Bishop M, Curington C, Toskes PP (1996): Fecal pancreatic elastase 1 is inaccurate in the diagnosis of chronic pancreatitis. Pancreas 13: 226-230

Ammann RW, Bühler H, Tuma J, Schneider J, Siebenmann R, Satz N (1981): Chronic and relapsing acute pancreatitis associated with chronic renal insufficiency and analgesic (phenacetin) abuse. Gastroenterol Clin Biol $\underline{5}$ : 509-514

Araki T, Ueda M, Ogawa K, Tsuji T (1992): Histological pancreatitis in end-stage renal disease. Int J Pancreatol 12: 263-269

Arvanitakis C, Nakos V, Kalekou-Greka H, Tourkantonis A (1988): Small intestinal function and structure in patients with chronic renal failure. Clin Nephrol $\underline{29}$ : 235-243

Avram MM (1977): High prevalence of pancreatic disease in chronic renal failure. Nephron 18: 68-71

Avram RM, Iancu M (1982): Pancreatic disease in uremia and parathyroid hormone excess. Nephron 32: 60-62

Baggenstoss AH (1948): The pancreas in uremia: a histopathologic study. Am J Pathol 24: 1003-1011

Bartos V, Melichar J, Erben J (1970): The function of the exocrine pancreas in chronic renal disease. Digestion $\underline{3}: 33-40$ 
Bradley III EL: The necessity for a clinical classification of acute pancreatitis: the Atlanta system; in: Acute pancreatitis. Diagnosis and therapy; hrsg. v. Bradley III EL. Raven Press, New York 1994, 27-32

Bruno MJ, van Westerloo DJ, van Dorp WT, Dekker W, Ferwerda J, Tytgat GNJ, Schut NH (2000): Acute pancreatitis in peritoneal dialysis and haemodialysis: risk, clinical course, outcome, and possible aetiology. Gut $\underline{46}$ : 385-389 Brydon WG, Kingstone K, Ghosh S (2004): Limitations of faecal elastase-1 and chymotrypsin as tests of exocrine pancreatic disease in adults. Ann Clin Biochem 41: 78-81

Camilleri M,Murray JA: Diarrhea and constipation; in: Harrison's principles of internal medicine; hrsg. v. Fauci AS, Kasper DL, Longo DL, Braunwald E, Hauser SL, Jameson JL, Loscalzo J. McGraw Hill Medical, New York etc. 2008, 245-255 Choi HS, Ham JS, Han DS, Son JH, Jun YC, Lee OY, Yoon BC, Lee MH, Kee CS, Park KN (1998): Clinical evaluation of faecal elastase 1 as an exocrine function test in the diagnosis of chronic pancreatitis (Abstr.). Gastroenterology 114: A447

Cuntz U, Frank G, Lehnert P, Fichter M (2000): Interrelationships between the size of the pancreas and the weight of patients with eating disorders. Int J Eat Disord 27: 297-303

Denneberg T, Lindberg T, Berg NO, Dahlquist A (1974): Morphology, dipeptidases and disaccharidases of small intestinal mucosa in chronic renal failure. Acta Med Scand 195: 465-470

Descos L, Duclieu J, Minaire Y (1977): Exocrine pancreatic insufficiency and primitive malnutrition. Digestion 15: 90-95

Dinoso VP, Jr., Murthy SNS, Saris AL, Clearfield HR, Lyons P, Nickey WA, Simonian S (1982): Gastric and pancreatic function in patients with end-stage renal disease. J Clin Gastroenterol 4: 321-324

Domínguez-Muñoz JE, Hieronymus C, Sauerbruch T, Malfertheiner P (1995): Fecal elastase test: evaluation of a new noninvasive pancreatic function test. Am J Gastroenterol 90: 1834-1837

Fischer B, Hoh S, dWehler M, Hahn EG, Schneider HT (2001): Faecal elastase-1: lyophilization of stool samples prevents false low results in diarrhoea. Scand J Gastroenterol $\underline{36}$ : 771-774 
Fölsch UR, Dreessen U-W, Talaulicar M, Willms B, Creutzfeldt W (1984): Effect of long-term fasting of obese patients on pancreatic exocrine function, gastrointestinal hormones and bicarbonate concentration in plasma. Z Gastroenterol 22: 357-364

Furkert JD, Zeier M, Schwenger V (2008): Gastrointestinal hemorrhage in hemodialysis patients. Z Gastroenterol $\underline{46}$ : 1266-1269

Gerhardt W, Stein G, Bosseckert H, Graupner C, Noske A (1974): Exkretorische Pankreasfunktion bei Niereninsuffizienz. Z Ges Inn Med 29: 895-899

Glasbrenner B, Schön A, Klatt S, Beckh K, Adler G (1996): Clinical evaluation of the faecal elastase test in the diagnosis and staging of chronic pancreatitis. Eur J Gastroenterol Hepatol $\underline{8}:$ 1117-1120

Goldstein DA, Horowitz RE, Petit S, Haldimann B, Massry S (1981): The duodenal mucosa in patients with renal failure response to $1.25(\mathrm{OH}) 2 \mathrm{D} 3$. Kidney Int $\underline{19}$ : 324-331

Gullo L, Ventrucci M, Tomassetti P, Migliori M, Pezzilli R (1999): Fecal elastase 1 determination in chronic pancreatitis. Dig Dis Sci 44: 210-213

Hahn J-U, Bochnig S, Kerner W, Koenig H, Sporleder B, Lankisch PG, Maisonneuve P, Lowenfels $A B$ (2005): A new fecal elastase 1 test using polyclonal antibodies for the detection of exocrine pancreatic insufficiency. Pancreas 30: 189-191

Kumar R, Banks PA, George PK, Tandon BN (1975): Early recovery of exocrine pancreatic function in adult protein-calorie malnutrition. Gastroenterology $\underline{68}$ : 1593-1595

Lankisch PG (1982): Progress report: exocrine pancreatic function tests. Gut 23: 777798

Lankisch PG (1993): Function tests in the diagnosis of chronic pancreatitis. Critical evaluation. Int J Pancreatol 14: 9-20

Lankisch PG (2004): Now that fecal elastase is available in the United States, should clinicians start using it? Curr Gastroenterol Reports $\underline{6}$ : 126-131

Lankisch PG, Schmidt I, König H, Lehnick D, Knollmann R, Löhr M, Liebe S (1998): Faecal elastase 1: not helpful in diagnosing chronic pancreatitis associated with mild to moderate exocrine pancreatic insufficiency. Gut 42: 551-554 
Lankisch PG, Mahlke R, Lübbers H, Lembcke B, Rösch W (2006): Leitsymptom Diarrhö (Zertifizierte medizinische Fortbildung). Dtsch Ärztebl 103: A261-A269 Lankisch PG, Weber-Dany B, Maisonneuve P, Lowenfels AB (2008): Frequency and severity of acute pancreatitis in chronic dialysis patients. Nephrol Dial Transplant 23: 1401-1405

Lankisch PG, Weber-Dany B, Hebel K, Maisonneuve P, Lowenfels AB (2009): The harmless acute pancreatitis score: A clinical algorithm for rapid initial stratification of non-severe disease. Clin Gastroenterol Hepatol 7: 702-705 Lembcke B, Braden B, Stein J (1994): Diagnostik der Steatorrhoe. Z Gastroenterol 32: 256-261

Löser C, Möllgaard A, Fölsch UR (1996): Faecal elastase 1: a novel, highly sensitive, and specific tubeless pancreatic function test. Gut 39: 580-586

Lüth S, Teyssen S, Forssmann K, Kölbel C, Krummenauer F, Singer MV (2001): Fecal elastase-1 determination: 'gold standard' of indirect pancreatic function tests? Scand J Gastroenterol 36: 1092-1099 
Magnusson M, Magnusson KE, Sundquist T, Denneberg T (1991): Impaired intestinal barrier function measured by differently sized polyethylene glycosis in patients with chronic renal failure. Gut 32: 754-759

Mössner J, Keim V, Niederau C, Büchler M, Singer MV, Lankisch PG, Göke B (1998): Leitlinien zur Therapie der chronischen Pankreatitis. Konsensuskonferenz der Deutschen Gesellschaft für Verdauungs- und Stoffwechselkrankheiten Halle, 21.-23. November 1996. Z Gastroenterol 36: 359-367

Otte M, Stahlheber H, Forell MM, Dobbelstein H, Richert J, Thurmayr R, Thurmayr GR (1975): Exokrine Pankreasfunktion bei chronischer Niereninsuffizienz. Klin Wochenschr 53: 67-72

Owyang C, Miller LJ, DiMagno EP, Mitchell III JC, Go VLW (1982): Pancreatic exocrine function in severe human chronic renal failure. Gut 23: 357-361

Poll M, Huber WW, Kempmann G, Willig F (1979): Exokrine Pankreasfunktion bei chronischer Niereninsuffizienz. Z Gastroenterol 17: 177-186

Quraishi ER, Goel S, Gupta M, Catanzaro A, Zasuwa G, Divine G (2005): Acute pancreatitis in patients on chronic peritoneal dialysis: an increased risk? Am J Gastroenterol 100: 2288-2293

Rasumowsky WJ (1899): Apoplexia pankreatis. Langenbecks Arch Klin Chir 모: 565587

Sachs EF, Hurwitz FJ, Block HM, Milne FJ (1983): Pancreatic exocrine hypofunction in the wasting syndrome of end-stage renal disease. Am J Gastroenterol $\underline{78}$ : 170-173

Sarner M, Cotton PB (1984a): Classification of pancreatitis. Gut 25: 756-759

Sarner M, Cotton PB (1984b): Definitions of acute and chronic pancreatitis. Clin Gastroenterol 13: 865-870

Sauniere J-F, Sarles H (1988): Exocrine pancreatic function and protein-calorie malnutrition in Dakar and Abidjan (West Africa): silent pancreatic insufficiency. Am J Clin Nutr 48: 1233-1238

Schimmelpfennig W, Schimmelpfennig R (1969): Über die Beziehungen zwischen Pankreas- und Nierenerkrankungen. Dtsch Gesundheitswesen 24: 393-399 
Schneider A, Funk B, Caspary W, Stein J (2005): Monoclonal versus polyclonal ELISA for assessment of fecal elastase concentration: pitfalls of a new assay. Clin Chem 51: 1052-1054

Shepherd AMM, Stewart WK, Wormsley KG (1973): Peptic ulceration in chronic renal failure. Lancet 301: 1357-1359

Stein J, Scheuermann EH, Yazdi R, Lembcke B, Caspary WF (1994): Reduced postheparin plasma diamine oxidase activity in patients with chronic renal failure. Z Gastroenterol 32: 236-239

Szepessy E, Sahin-Tóth M (2006): Inactivity of recombinant ELA2B provides a new example of evolutionary elastase silencing in humans. Pancreatology $\underline{6}$ : 117122

Talamini G, Uomo G, Pezzilli R, Rabitti PG, Billi P, Bassi C, Cavallini G, Pederzoli P (1999): Serum creatinine and chest radiographs in the early assessment of acute pancreatitis. Am J Surg 177: 7-14

Tandon BN, George PK, Sama SK, Ramachandran K, Gandhi PC (1969): Exocrine pancreatic function in protein-calorie malnutrition disease of adults. Am J Clin Nutr 22: 1476-1482

Tandon BN, Banks PA, George PK, Sama SK, Ramachandran K, Gandhi PC (1970):

Recovery of exocrine pancreatic function in adult protein-calorie malnutrition. Gastroenterology 58: 358-362

Van de Kamer JH, ten Bokkel Huinink H, Weyers HA (1949): Rapid method for the determination of fat in feces. J Biol Chem 177: 347-355

Vaziri ND, Dure-Smith B, Miller R, Mirahmadi M (1987): Pancreatic pathology in chronic dialysis patients - an autopsy study of 78 cases. Nephron $\underline{46}$ : 347349

Ventrucci M, Campieri C, Di Stefano M, Ubalducci GM, Bassi SL, Di Grazia A, Giudicissi A, Festi D (1995): Alterations of exocrine pancreas in end-stage renal disease. Do they reflect a clinically relevant uremic pancreopathy? Dig Dis Sci 40: 2576-2581

Ventrucci M, Cipolla A, Middonno M, Racchini C, Simoni P, Afandi K, Grammatico F, Campieri C (2000): Impaired fecal elastase excretion in uremic pancreopathy. Dig Dis Sci 45: 2265-2269 
Wasse H, Gillen DL, Ball AM, Kestenbaum BR, Seliger SL, Sherrard D, Stehman-Breen CO (2003): Risk factors for upper gastrointestinal bleeding among end-stage renal disease patients. Kidney Int 64: 1455-1461

Wisotzky J, Bosseckert H, Jansa U, Stein G (1996): Pankreasveränderungen bei chronischer Nephritis mit und ohne Analgetikaabusus. Nieren- und Hochdruckkrankh 25: 82-86

Wittich K-A, Schmidt H, Scheler F, Creutzfeldt W (1968): Exokrine Pankreasfunktion bei chronischer Niereninsuffizienz. Verh Dtsch Ges Inn Med 74: 1072-1074

Wizemann V, Benz U (1978): Gastrointestinale Befunde bei chronisch niereninsuffizienten Patienten. Med Welt 29: 1025-1029 


\section{Danksagung}

Allen, die zum Gelingen dieser Arbeit beigetragen haben, möchte ich meinen Dank aussprechen.

Ganz besonders möchte ich meinem Doktorvater, Herrn Professor Dr. Paul Georg Lankisch, danken, der mir freundlicherweise nicht nur das Thema überlassen, sondern mich auch vom ersten Tag an ganz außerordentlich und mit viel Geduld unterstützt hat und jederzeit eine Antwort auf meine Fragen hatte.

Herrn Professor Dr. Patrick Maisonneuve, Mailand, danke ich für die freundliche Unterstützung bei der statistischen Auswertung der Daten.

Besonderer Dank gilt Frau Jutta Otto im Pankreaslabor des Universitätsklinikums in Göttingen, die in allen Belangen der in der Arbeit notwendigen Laboruntersuchungen federführende und absolut akribische Unterstützung gewesen ist.

Mein Dank geht auch an die Dialysepatienten unserer Praxis. Für viele von innen war es eine Selbstverständlichkeit, ihrem Arzt zu helfen und vorbehaltlos am praktischen Teil der Arbeit teilzunehmen. Auch dem Pflegepersonal gilt Dank für die geduldige Unterstützung und das Ertragen der Geruchsbelästigung.

Meinen Eltern und meiner Frau Esther danke ich für das kritische Durchsehen der Arbeit. 


\section{Lebenslauf}

Am 15.03.1966 wurde ich in Bad Wildungen als erster Sohn des Internisten Dr. Hans-Joachim Griesche und der Schneiderin Edith Griesche, geb. Eckell, geboren.

Von 1972 bis 1976 besuchte ich die Grundschule Helenental und anschlieBend das Gustav-Stresemann-Gymnasium in Bad Wildungen, wo ich im Juni 1985 die Allgemeine Hochschulreife erlangte.

Nach der Durchführung verschiedener Praktika begann ich im Oktober 1987 das Studium der Humanmedizin an der Universität Hamburg, legte am 13.09.1989 die Ärztliche Vorprüfung, am 30.08.1990 das Erste Staatsexamen und am 25.08.1992 das Zweite Stattsexamen ab. Ich beendete mein Studium am 29.11.1993 mit dem dritten Staatsexamen und der Erlangung der Approbation als Arzt.

Von Januar bis Oktober 1994 arbeitete ich als Arzt im Praktikum in der Gefäßchirurgischen Abteilung des Stadtkrankenhauses Bad Wildungen und wechselte zum November 1994 in die Allgemeinchirurgische Abteilung, wo ich bis Ende März 1995 tätig war.

Von April 1995 bis November 1996 war ich, zunächst noch als Arzt im Praktikum, später als Assistenzarzt, in der dortigen Nephrologischen Abteilung tätig und begann dort die Weiterbildung zum Facharzt für Innere Medizin, die ich ab November 1996 bis Ende Dezember 1999 in der Abteilung für Innere Medizin des Kreiskrankenhauses Dannenberg fortsetzte. Dort erlangte ich auch im September 1999 die Zusatzbezeichnung „Rettungsmedizin“ der Ärztekammer Niedersachsen.

Von Januar 2000 bis Juni 2001 war ich anschließend als Assistenzarzt in der Klinik für Innere Medizin am Städtischen Klinikum Lüneburg beschäftigt. Zum Juli 2001 wechselte ich in die nephrologische Praxis Lüneburg; dort war ich bis zum März 2003 als Weiterbildungsassistent tätig, seit 01.04.2003 bin ich in dieser Praxis als niedergelassener Nephrologe tätig. 
Seit 02.07.2002 bin ich Facharzt für Innere Medizin (Ärztekammer Niedersachsen), seit 30.01.2003 führe ich die Zusatzbezeichnung "Nephrologie“ (Ärztekammer Niedersachsen), seit dem 16.12.2005 die Bezeichnung „Hypertensiologe DHL“.

Seit Oktober 1998 bin ich mit Esther Philippi, Förderschullehrerin, verheiratet. Wir haben zwei gemeinsame Kinder, eine Tochter, 8 Jahre, und einen Sohn, 5 Jahre alt. 